\title{
Neuroscience of Imagination and Implications for Human Evolution
}

\author{
Andrey Vyshedskiy \\ Boston University, Boston, USA
}

\begin{abstract}
Vivid dreaming often conjures-up imaginary novel images during the sleep. Humans can also imagine novel mental images consciously and purposefully in the process of Prefrontal Synthesis (PFS). Despite both processes commonly referred to as 'constructive imagination,' their mechanisms of mental image creation are very different. PFS is completely dependent on the lateral prefrontal cortex (LPFC) and patients with damage to the LPFC often lose their PFS ability. Conversely, dreaming is not controlled by the LPFC: the LPFC is inactive during the sleep and patients whose LPFC is damaged do not notice any change in their dreams. Other neurobiologically distinct components of imagination discussed in this manuscript include amodal completion, categorically-primed spontaneous imagination, integration of modifiers and mental rotation, and prefrontal analysis. Clearer neurobiological definitions of separate imagination mechanisms can lead to better understanding of hominin evolution and better educational strategies in children with neurodevelopmental delays.
\end{abstract}

Keywords: comparative cognition, cognitive neuroscience, developmental psychology, evolution of imagination, Language evolution, human evolution, recursive language, flexible syntax, human language, syntactic language, modern language, neurolinguistics, default mode network, mind-wondering, lucid dreaming, daydreaming, task-negative network

\section{Top-down Imagination Versus Bottom-Up Imagination}

History provides many examples of dream-inspired discoveries. Otto Loewi dreamed of an experiment that proved chemical transmission of nerve impulses. He immediately went to his lab to perform the experiment and later received the Nobel Prize for this discovery. Elias Howe, the inventor of the first sewing machine, has claimed that the main innovation, placing the thread hole near the tip of the needle, came to him in a dream. The chemist Friedrich Kekulé discovered the ring shape of the benzene molecule after having a dream of a snake seizing its own tail.

What is special about the mechanism of dreams that sometimes results in insights not forthcoming during waking? It turns out that during waking most of mind's internal imagery is controlled from the front of the brain by the so-called executive control network. Reasoning, planning, and strategizing is the result of the constructive imagination conducted by the lateral prefrontal cortex (LPFC, Figure 1), which acts like a puppeteer assembling objects stored in memory into novel combinations.

The vivid dreaming of rapid eye movement (REM) sleep, on the other hand, is driven from the regions in the back of the brain (the posterior cortex). Neuroimaging observations show that the LPFC is inactive during the sleep [1,2]. Furthermore, in people whose LPFC is damaged, dreams do not change at all, confirming that LPFC does not control dreaming [3]. With no control from the LPFC during REM dreaming, objects from memory can combine into novel unexpected formations resulting in sudden insights. The memory of a dream is short-lived, but if one wakes up during an insight, they can consolidate the "vision" into long-term memory and come up with an important discovery.

A peculiar conclusion is that both processes, imagination during waking and imagination during dreaming, can arrive at the same novel mental image: the visual image can be constructed during a dream by the posterior cortex through the bottom-up mechanism and can be also driven by the LPFC during waking through a top-down mechanism. Note that the end result of both processes is the formation of a novel fantasy, an unreal image. It is probably for this reason that we commonly refer to both processes as "imaginary experience" or "constructive imagination." But while the final fantasy products of both types of constructive imagination may be identical, the neurological mechanisms by which an individual arrives at the novel mental image during waking and during dreaming are different. To distinguish these mechanisms, we will refer to the bottom-up imagination during REM sleep as REM sleep dreaming (or simply dreaming, Figure 2) and to the top-down conscious purposeful imagination controlled by the LPFC as Prefrontal Synthesis (PFS, we have previously referred to the same process as Mental Synthesis [4]. The word synthesis is used to emphasize the purposeful nature of this mechanism 


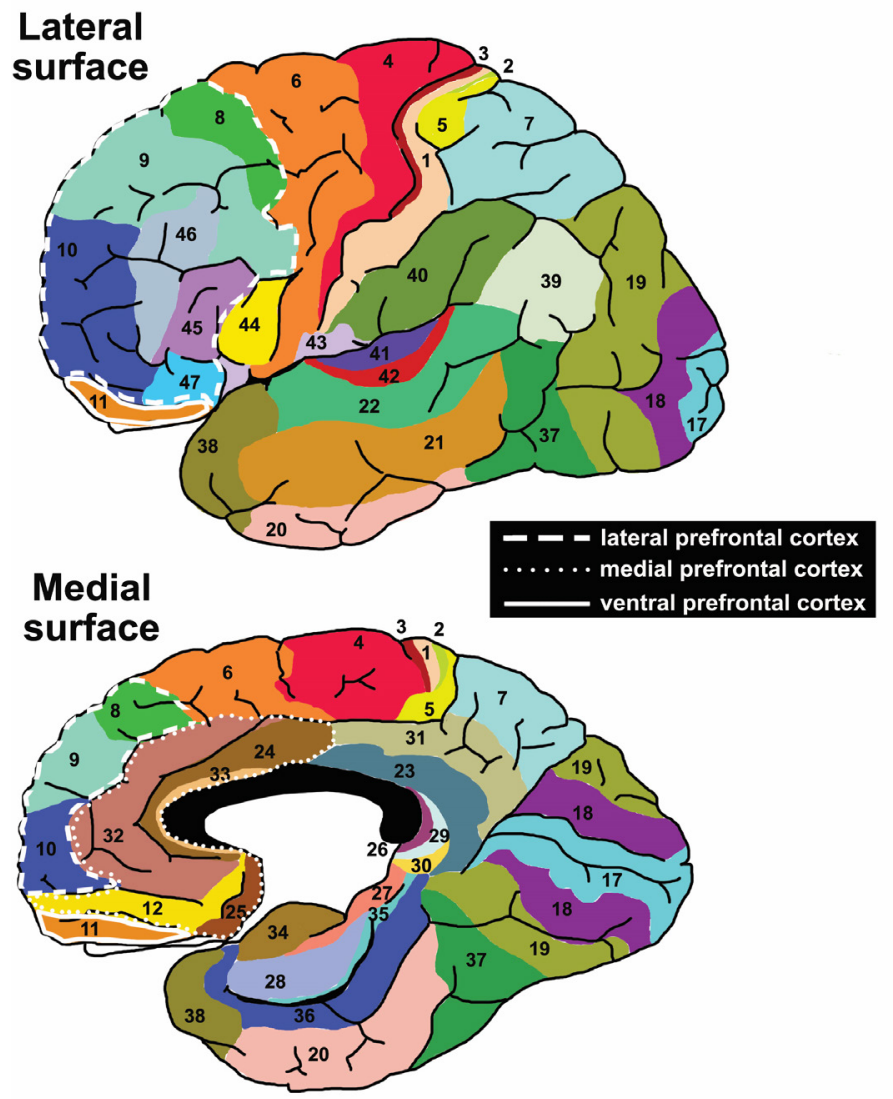

Figure 1. The PFC definition in this article follows Striedter (2004) [5] delineation of the PFC into two functionally, morphologically, and evolutionarily different regions: the phylogenetically older ventromedial PFC (vmPFC) that is present in all mammals and the phylogenetically newer lateral prefrontal cortex ( $L P F C)$, that is present only in primates. The vmPFC is primarily concerned with inhibition of urges, motivation, identification of rewarding or otherwise significant stimuli, as well as mood and empathy. The LPFC is primarily involved in working memory, reasoning, planning, and active forms of imagination.

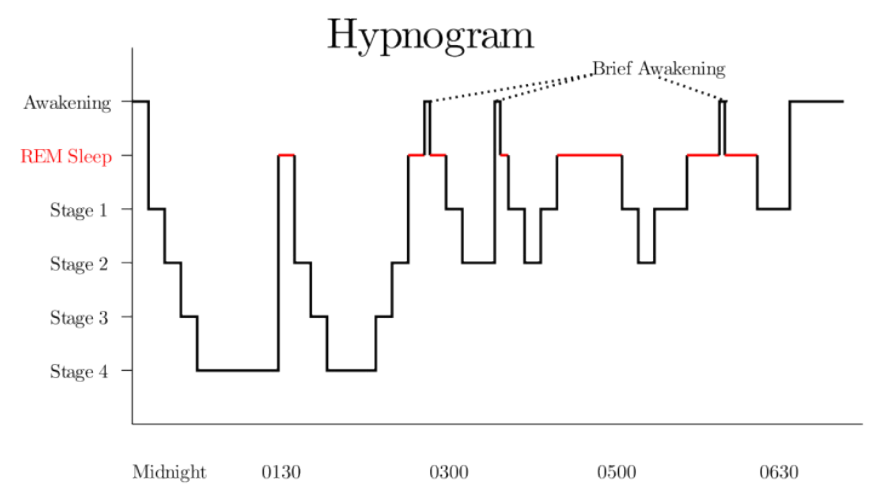

Figure 2. Sleep dreaming. Since we usually wake up during REM sleep, the vivid bizarre REM sleep dreams are the most common type of dreams that we remember. The other type of dreams includes more static, thought-like dreams experienced during deep slow-wave sleep (Stage 3 and 4). These dreams are primarily driven by the hippocampus in the process of long-term memory consolidation and predominantly include memories of events "as they happened" without the random novel combination of objects seen in REM sleep dreams. Since the main goal of this manuscript is to discuss mechanisms of imagination of novel objects and scenes, we focus on REM sleep dreaming and skip the deep slow-wave sleep dreams completely. Illustration by Razer M, CC BY-SA 3.0, https://commons.wikimedia.org/w/index.php? curid $=17745252$ of imagination. Just like a ribosome synthesizes amino acids into a protein using a program described in a mRNA, the LPFC synthesizes objects stored in memory into novel combinations using the program described in a heard sentence.)

\section{The Extended Binding-By-Synchrony Hypothesis: Synchronization of Neuronal Ensembles Is Responsible For All Mechanisms Of Constructive Imagination}

The scientific consensus is that each familiar object is encoded in the brain by a network of neurons known as a neuronal ensemble [6]. The sensory component of each object stored in memory is physically encoded by neurons of the posterior cortex, that was auspiciously named by Christof Koch and colleagues 'the posterior cortical hot zone' for its ability to single-handedly generate conscious experience [7]. When one recalls any object, the object-encoding neuronal ensemble (objectNE) in the posterior cortical hot zone activates into synchronous resonant activity that results in conscious perception of the object [8], Figure 3. The neuronal ensemble binding mechanism, based on the Hebbian principle "neurons that fire together, wire together," came to be known as the Binding-by-Synchrony (BBS) hypothesis [9,10]. However, while the Hebbian principle explains how we perceive a familiar object, it does not explain the infinite number of novel objects that humans can imagine. To account for the limitless constructive imagination, it was proposed that synchronization of independent objectNEs is a general mechanism underlying any novel imaginary experience $[4,11]$. When the synchronization of independent objectNEs is driven from the front by the LPFC, we refer to it as PFS; when the synchronization is driven from the back, we refer to it as dreaming or hallucination. The synchronization hypothesis has never been directly tested but is indirectly supported by several lines of experimental evidence [12-16]. Furthermore, it is the most parsimonious way to explain the formation of new memories of imaginary experiences since the same mechanism of Hebbian learning ("neurons that fire together wire together") that is responsible for externally-driven sensory memories of objects and scenes can be also responsible for memorizing internally-constructed novel images, such as plans and engineering designs. In the process of formation of novel receptive memories, neurons are synchronized by simultaneous external stimulation (e.g., light reflected from a moving object is falling on the retina at the same time). In the process of formation of novel imaginary memories, neurons are synchronized by the LPFC during waking or spontaneously during dreaming. In both cases it is the synchronous firing of neurons that wires them together into new stable objectNEs that can later be consolidated into long-term memory. We will refer to this model as the 'Extended Binding-BySynchrony' (EBBS) hypothesis.

\section{Theoretically Possible Mechanisms of Imagination}

In this section, we hypothesize on various mechanisms of imagination theoretically possible under the EBBS hypothesis. The list is not exhausted by PFS and dreaming, but includes various other mechanisms. 

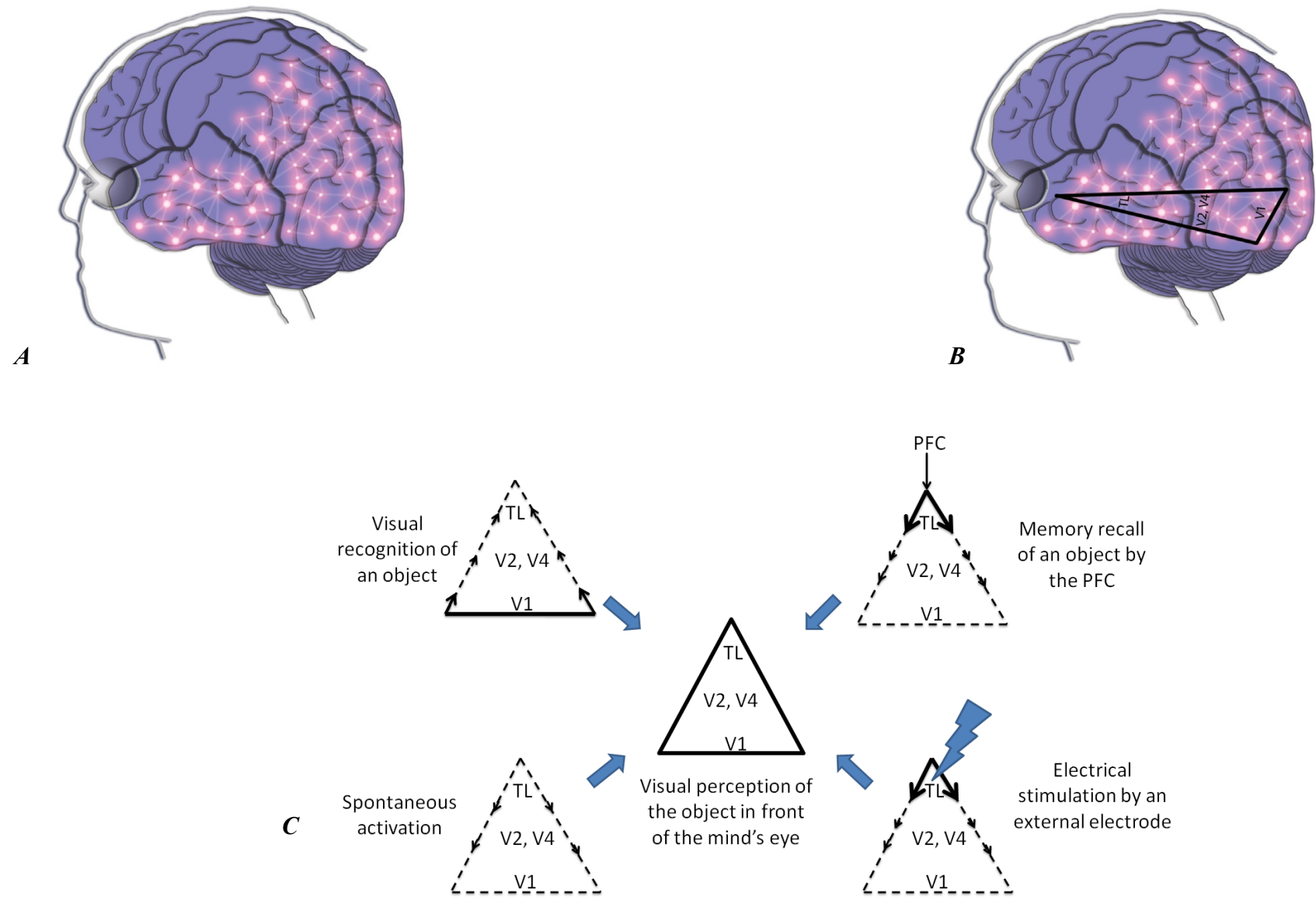

Figure 3. (A) Conscious experience is closely associated with the activity in the cerebral cortex. The back part of the cortex (the occipital, parietal and temporal cortexes, together referred to as the posterior cortex) is particularly active during conscious experience and lesions to the posterior cortex often results in loss of whole modalities of conscious experience. Therefore, most sensory conscious experience is thought to be generated by neurons in the posterior cortex. (B) Our visual world consists of meaningful, unified, and stable objects that move coherently as one piece. Objects, therefore, are thought to constitute the functional units of perception [17]. To encode complete objects, including their shape, color, texture, and other sensory properties, neurons in the posterior cortex are organized by enhanced connections into neuronal ensembles [18,19], depicted here as a pyramid with a bottom in the occipital lobe and an apex in the temporal lobe. (C) According to the Bindingby-Synchrony (BBS) hypothesis, an object can be perceived in front of the mind's eye, when neurons of the object-encoding neuronal ensemble (objectNE) fire in synchrony $[9,10,20]$. This synchronous firing can be a result of (clockwise from the top left corner) simple visual recognition of an object present in the visual field, voluntary recall of an object by the PFC [21,22], electrical stimulation of the cortex of temporal lobe by an external electrode [23], or spontaneous activation.

\section{Top-down mechanisms of imagination}

Prefrontal Synthesis: As defined above, PFS involves spatial combination of two or more objects from memory into a novel mental image. The mechanism of PFS under the EBBS hypothesis involves the LPFC-orchestrated synchronization of independent objectNEs to fire in-phase with each other [4]. When two or more independent objectNEs are activated to fire synchronously, they are consciously experienced as one unified object or scene. In this process humans can purposefully manufacture an unlimited number of novel mental images and can plan their future actions through mental simulation of the physical world. The LPFC can be viewed as a puppeteer controlling its puppets (memories encoded in objectNEs stored in the posterior cortex). By pulling the strings, the LPFC puppeteer activates and changes the firing phase of the objectNEs puppets. Phase-synchronized objectNEs are consciously experienced as a novel whole object or scene. For example, to imagine something that you have never seen before, such as your favorite cup on top of your computer's keyboard, your LPFC (1) activates the neuronal ensemble of the cup, (2) activates the neuronal ensemble of the keyboard, and then (3) synchronizes the firing of the two ensembles, Figure 4.

PFS is essential for many cognitive functions, including the understanding of flexible syntax. Consider the two sentences: "A dog bit my friend" and "My friend bit a dog." It is impossible to distinguish the difference in meaning using words or grammar alone, since both, the words and grammatical structure are identical in these two sentences. Understanding the difference in meaning and appreciating the misfortune of the $1^{\text {st }}$ sentence and the humor of the $2^{\text {nd }}$ sentence depends on the LPFC ability to flexibly synthesize novel mental images according to a presented description. Only after the LPFC forms 
1
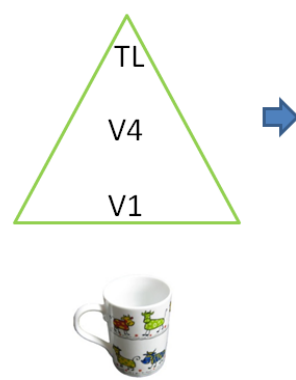

2
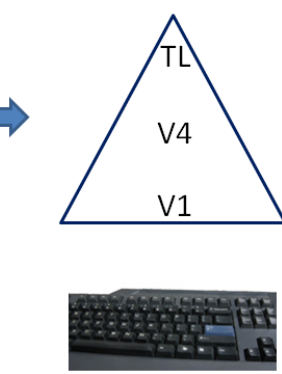

3
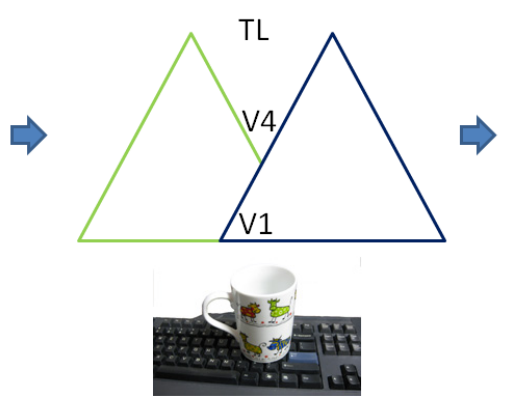

4
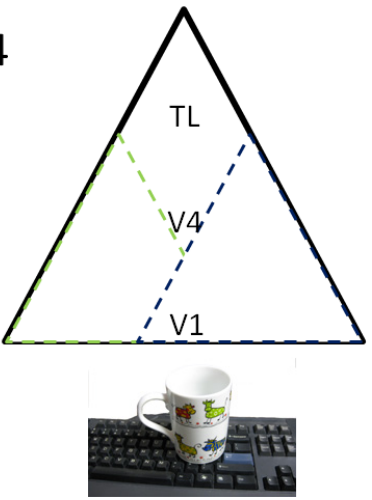

Figure 4. Prefrontal Synthesis of the cup on top of the keyboard:

Step 1: Recall of the cup: when the objectNE representing the cup (shown as green triangle) is activated into synchronous firing, the cup is perceived.

Step 2: Recall of the keyboard: when the objectNE representing the keyboard (shown as blue triangle) is activated into synchronous firing, the keyboard is perceived.

Step 3: When the two objectNEs are synchronized together, the two mental objects are fused, and a new, never-seen-before mental image of the cup on top of the keyboard is perceived.

Step 4: The connections between the two synchronously activated objectNEs are strengthened and, thus, the new objectNE representing the cup on top of the keyboard is formed (black pyramid). This objectNE will be stored in memory and can be activated at a later time as one unit.

these two different images in front of the mind's eye, are we able to understand the difference between these two sentences.

PFS is also essential for understanding of spatial prepositions. For example, the request "to put a green box \{inside/behind/on top of $\}$ the blue box" requires an initial mental simulation of the scene and only then is it possible to correctly arrange the physical objects. An inability to produce a novel mental image of the green box \{inside/behind/on top of the blue box would lead to the use of trial-and-error, which in majority of cases will result in an incorrect arrangement.

In its spirit, PFS is similar to Chomskyan Merge [24]. This is, however, where similarity ends. Merge is defined linguistically as a combination of any two syntactic objects to create a new one. PFS, on the other hand, is defined neurobiologically. An individual does not need to know the names of objects in order to combine them mentally into a novel hybrid object or scene. One can mentally combine objects of strange geometrical shape that do not have names in any language. Merging of objects in mental space does not directly depend on knowledge of any language.

Even when language is used to direct PFS in the mind of a listener, PFS definition is different from Merge. For example, combination of an adjective and a noun is a Merge operation, but does not fall under PFS that must always involve combination of two or more independent objects. Furthermore, PFS, but not Merge, requires creating a novel mental hybrid object or scene. For example, a sentence 'ship sinks' can be understood by remembering a previously seen picture of a sinking ship and thus, completely avoiding the PFS process. Under Chomskyan theory, 'ship sinks', however, is considered a Merge operation since the sentence merges a determiner phrase 'ship' and a verb 'sinks' to create a sentence 'ship sinks.'

In neurobiological terms, Merge operation is defined in such a way that it utilizes three brain regions: Wernicke's area that primarily links words with objects; Broca's area that interprets the grammar and assigns words in a sentence to a grammatical group such as noun, verb, or preposition [25]; and the LPFC that synthesizes the objects from memory into a novel mental image according to grammatically imposed rules $[11,26]$. Crucially, PFS definition leaves out interpretation of grammar in the Broca's area and leaves out linking words with objects in the Wernicke's area. PFS definition limits it to the function of the LPFC.

The difference between PFS and Merge is also highlighted by the process of learning a new language in adulthood: when one studies German, Spanish or Italian, one learns new words (Wernicke's area) and new grammar rules (Broca's area), PFS however does not change a bit. The same PFS ability can be used to understand German, Spanish, or Italian sentences. Thus, PFS is defined significantly more narrowly than the Merge operation in both neurological and linguistic terms.

Modification of a single objectNE: integration of modifiers and mental rotation: Close your eyes and recall your car. Now imagine your car in different colors: blue, red, yellow. The mechanism of changing the color does not fall under the definition of PFS since only a single object is involved - your car. Under the EBBS hypothesis, integration of modifier, such as a color, involves the LPFC-orchestrated synchronization of a single objectNE and another group of neurons encoding its color in the ventral visual cortex [27]. When the LPFC shifts the neurons encoding the color to fire in-phase with the objectNE, synchronized neurons encoding the color $\{$ blue/red/yellow $\}$ and the shape of the car are experienced as a complete image of a car in blue, red, or yellow color and this novel image is stored in memory, Figure 5.

A similar mechanism is theorized by the EBBS hypothesis to be responsible for purposeful mental metamorphoses of an object's size, number, and rotation $[11,26]$. 

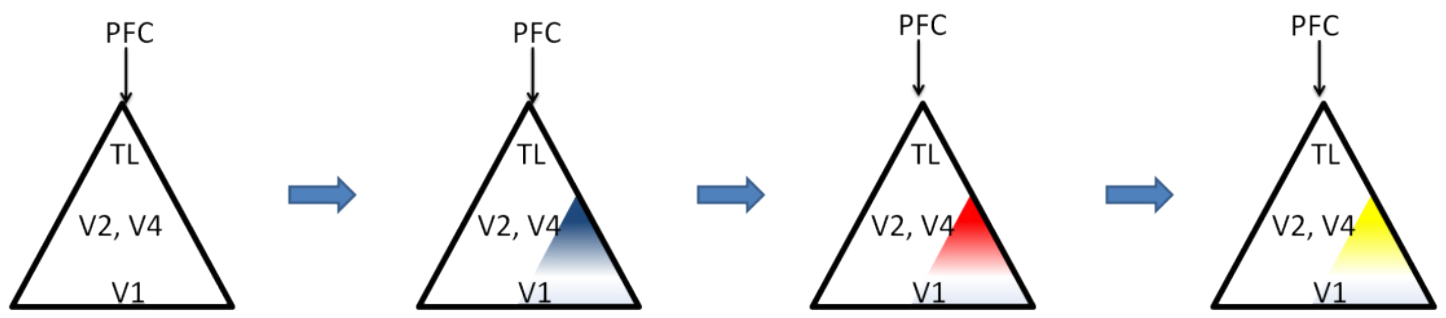

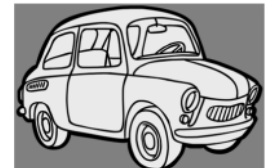

Visual perception of a car

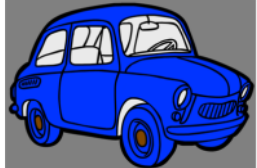

Visual perception of the blue car

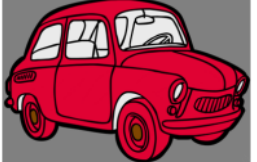

Visual perception of the red car

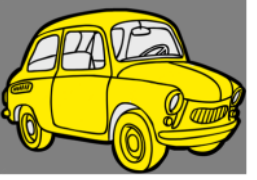

Visual perception of the yellow car

Figure 5. Integration of modifiers. According to the EBBS hypothesis, imagining a car in blue, red, or yellow color requires the LPFC-orchestrated synchronization of the car-encoding objectNE and various color encoding neurons in V4.

Prefrontal Analysis: While following the steps of Alice in Wonderland, recall your kettle and imagine a broken handle. Magically, the good old kettle turns in your mind into a broken stump with no handle. Under the EBBS hypothesis, this transformation involves desynchronization of the part of an objectNE encoding the handle from the rest of the objectNE of the kettle, Figure 6. Since this process is mediated by the LPFC, we call it Prefrontal Analysis (PFA, analysis involves the disassembly of an object into parts as opposed to synthesis, which involves combining two or more objects together). LPFC-driven shift of a part of the objectNE out-of-phase with the rest of the ensemble, results in the perception of a new object encoded by those neurons that remain firing synchronously. The new object is a novel imaginary object since you have never physically observed it.

\section{Bottom-up mechanisms of imagination}

REM sleep dreaming: PFS, integration of modifiers, mental rotation, and PFA are all examples of top-down LPFCcontrolled imagination. Conversely, during REM sleep, when the LPFC is inactive [1,2] and the communication between neocortex and hippocampus is disrupted by high ACh level [28], objects appearing in one's perception must be mediated by activation of previous memories encoded in objectNEs in the posterior hot zone. It is unclear how exactly those objectNEs jump up into activity. A common explanation is that objectNEs, primed by previous activity or current sensory or subcortical stimulation, activate spontaneously, triggered by the pontogeniculo-occipital (PGO) waves that characterize REM sleep [29]. In the words of Hobson \& McCarley, the neocortex is making "the best of a bad job in producing even partially coherent dream imagery from the relatively noisy signals sent up from the brain stem" [30]. It is also commonly accepted that the intensity of dreams during REM sleep can be dialed up or down by the dopaminergic cells of the ventral tegmental area. For example, drugs that block activity in the dopaminergic activity (e.g., haloperidol) inhibit unusually frequent, and vivid dreaming, while increase of dopamine (e.g., through 1-dopa) stimulates excessive vivid dreaming and nightmares [31].

This manuscript, however, is not concerned with the exact reason why a specific objectNE is activated during REM sleep. The main issue herein is how those objectNEs hybridize into novel images. The EBBS hypothesis predicts that objectNEs that spontaneously activate in-synchrony will be perceived together as novel combined objects or scenes. In other words, the objectNEs firing spontaneously and asynchronously from each other are perceived as separate objects; however, if by accident, two disparate objectNEs fire in-sync with each other, they are perceived as a novel hybrid object. In this process, an unlimited number of bizarre hybrid mental images can form during REM sleep.

Amodal completion: Another mechanism of bottom up imagination involves so-called amodal completion. In the example shown in Figure 7, most people perceive a long cat wrapped around a column. The missing parts of contours are filled in or imagined by the posterior cortex and the "long cat" is perceived in an act of posterior cortex defiance to the logical LPFC.

Categorically-primed spontaneous imagination: In addition to clearly top-down (PFS, integration of modifiers, mental rotation, and PFA) and unambiguously bottom-up (REM sleep dreaming, amodal completion) types of imagination, the EBBS hypothesis anticipates hybrid mechanisms as well. For example, the LPFC, known to encode categorical features (such as 'things that protect you from the rain') [21,32], can prime the whole category of objectNEs, without activating any specific objectNE, Figure 8. Just as in a dream, primed objectNEs fire randomly; the objectNEs that happen to fire in synchrony, are predicted to be perceived as unified complete hybrid novel mental images and scenes. Conspicuous examples of categorically-primed spontaneous imagination include impulsive fantasizing about food or drugs, spontaneous sexual fantasies, racing thoughts about an upcoming exam, an anxiety 

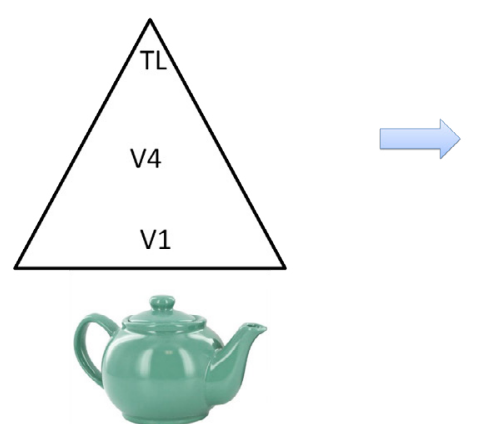

Figure 6. Prefrontal Analysis of a tea kettle. According to the EBBS hypothesis, mentally breaking off a handle from a tea kettle involves desynchronization of the handle-encoding neurons from the kettle object $N E$.

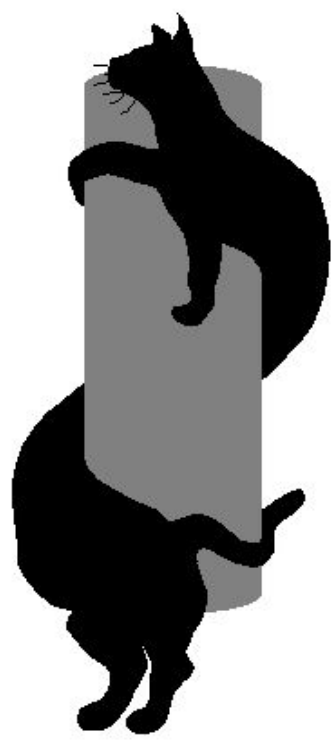

Figure 7. In this picture most people spontaneously imagine missing contours and perceive a long single long cat wrapped around a column.

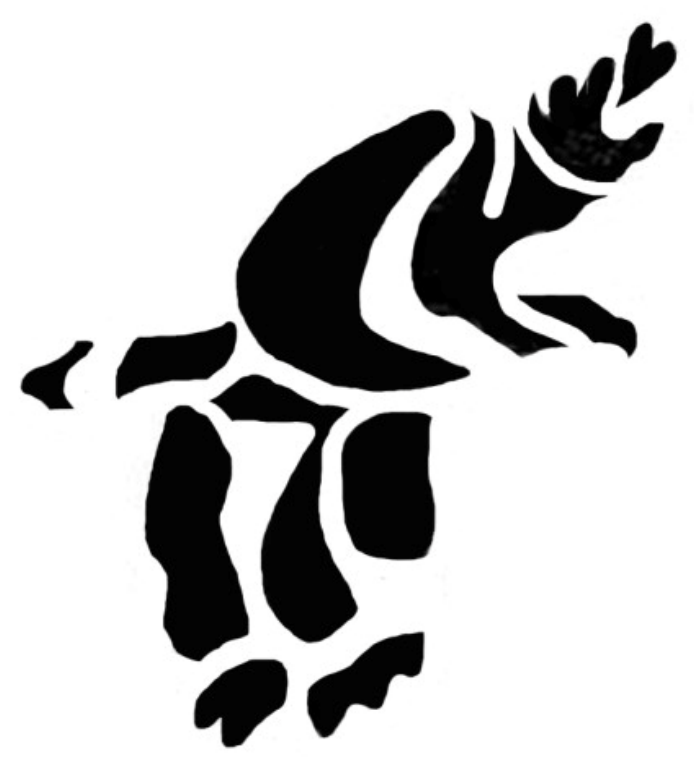

Figure 8. Most people hesitate to recognize an object displayed in this figure. However, once one category of objectNEs is primed by the LPFC, the object is easily recognized. When you are ready to be primed by reading the object's category, please scroll to Figure 9. over a missing child, compulsive jealousy, and many other obsessions. When such an obsession overtakes the brain, one category of objectNEs is primed and imagery is a fantasy, resulting from spontaneous firing of these primed objectNEs in the posterior cortex.

The categorically-primed spontaneous imagination is also likely to be one of the common mechanisms of scientific insight: instead of serial purposeful PFS, one can let their mind wonder while priming fantasies along few categories of interest. The resulting semi-spontaneous neuronal firing results in synchronization of previously independent objectNEs and provides new ideas for scientific enquiry. Sometimes we may even experience the "Aha!" moment alike to Archimedes who shouted "Eureka!" when he suddenly discovered that water displacement could be used to calculate density.

Contemporary research on insight uses a variety of verbal and physical tasks [33-35]. Mark Jung-Beeman and colleagues have examined the neural bases of these Eureka moments and reported increased activity associated with insight moments in the right hemisphere temporal cortex [36]. Interestingly, just prior to reporting the insight, individuals had a sudden burst of high-frequency gamma-band neural activity in the same area. This increased gamma-band neural activity may be associated with synchronization of objectNEs that allows individuals to see connections that previously eluded them.

Earl K. Miller brilliantly summarized these "Aha!" moments of scientific inquires when he was asked how he was finding his inspiration: "I don't. Inspiration finds you, most often when you're not trying to find it. Many times, inspiration and decisionmaking are the result of unconscious processes churning away at something. Your conscious mind then receives the result. In fact, your conscious mind can often get in the way by forcing you down the same well-worn paths. Inspiration often comes when your conscious mind is not engaged by the question at hand. This is why we often get ideas when we are drifting off to sleep, or walking to work in the morning, etc. One of the central ideas of my most cited paper [37] came to me suddenly at a bar in Vancouver. Good thing there was a cocktail napkin nearby [38]."

\section{Dissociation of top-down and bottom-up imagination mechanisms in patients with LPFC lesions}

Perhaps the most striking feature of dreaming is how similar the experience generated by dreams is to the real world. In fact, at times, the dreamer might be in doubt whether they are asleep or awake. The reason for this is straightforward: PFS and dreaming hallucinations share the neurological substrate that generates the sensory experience with all its video-spatial and auditory features, namely the posterior cortex hot zone. Accordingly, lesions in the posterior cortex often result in parallel decline in waking visuo-spatial abilities and dreaming [39]. For example, lesions in specific regions of the posterior cortex that underlie deficits in visual perception are associated with corresponding deficits in dreaming [31]. Individuals with lesions in the V4 
region who do not perceive color, dream in black-and-white; those who do not perceive motion as a consequence of V5/ MT lesion do not dream of motion; and subjects with impaired face perception as a consequence of fusiform gyrus lesion, do not dream of faces [3,31]. Furthermore, global cessation of dreaming commonly follows large lesions in or near the temporo-parieto-occipital junction [31], the region where a large part of objectNEs are located. The logical consequence of damage to temporo-parieto-occipital junction is a significant reduction of the ability of objectNEs to organize into resonant synchronous activity essential for sensory recollection of these objects. Predictably, this at the same time results in inability to recall those objects and also inability to dream about them.

While the posterior cortex is shared by waking and dreaming imaginations, other brain regions are essential for one, but not the other imagination mechanism. For example, patients with damage to the LPFC sparing most of Broca's area often present a very specific PFS deficit, that affects both their language and ability to reason. Joaquin Fuster calls this alteration in language "prefrontal aphasia" [40] and explains that "although the pronunciation of words and sentences remains intact, language is impoverished and shows an apparent diminution of the capacity to 'propositionize.' The length and the complexity of sentences are reduced. There is a dearth of dependent clauses and, more generally, an underutilization of what Chomsky characterizes as the potential for recursiveness of language" [40].

Alexander Luria calls this condition "frontal dynamic aphasia" [41] and reports that "these patients had no difficulty grasping the meaning of complex ideas such as 'causation,' 'development,' or 'cooperation.' They were also able to hold abstract conversations. But difficulties developed when they were presented with complex grammatical constructions which coded logical relations. ... Such patients find it almost impossible to understand phrases and words which denote relative position and cannot carry out a simple instruction like 'draw a triangle above a circle [42].",
In addition to language alterations, individuals with LPFC lesions often show deficit in reasoning revealed by nonverbal IQ tests. These individuals may have normal full-scale IQ, but commonly exhibit a selective and catastrophic deficit in tasks relying on PFS, such as matrix reasoning tasks requiring integration of multiple objects [43], such as those shown in Figure 9. Individuals with PFS disability invariably fail these integration tasks and, therefore, typically perform below the score of 85 in non-verbal IQ tests [44].

Crucially, individuals with LPFC damage and the associated PFS disability do not report changes in their dreaming [3]. They continue to experience the same vivid REM dreams that they experienced before the lesion. This observation is consistent with neurobiological dissociation between mechanisms of a top-down and bottom-up imagination.

\section{Conclusions}

At least six different mechanisms of imagination are predicted by the EBBS hypothesis. On an axis of their dependence on the LPFC, imagination mechanisms range from completely LPFC-independent spontaneous REM sleep dreaming to the LPFC-dependent PFS. In between these extremes lies a panoply of mechanisms with gradually increasing role of the LPFC: amodal completion, categorically-primed spontaneous insight, integration of modifiers and mental rotation, and PFA (Figure 10).

\section{Evolution of Imagination}

\section{Top-down mechanisms of imagination}

Prefrontal Synthesis acquisition: While it is clear that all mechanisms of imagination are available to modern humans, it is also clear that not all mechanisms of imagination are available to all animals. The goal of this section is to analyze when PFS could have evolved. Archeological records indicate gradual, piecemeal process of accretion of symbolic artifacts such as perforated shells [45], use of pigments [45], and intentional burials [46] over hundreds of thousands of years [47]. However, symbolic thinking is not congruent to PFS. The symbolic use of objects can be accompanied by PFS in modern individuals,
A

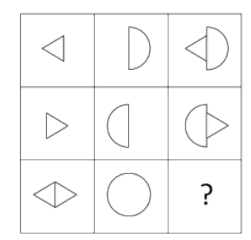

B

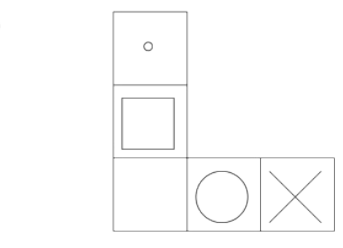

C

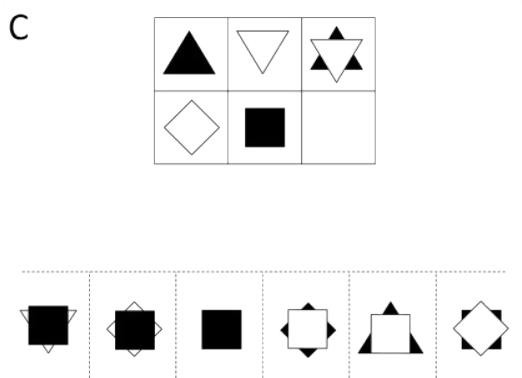

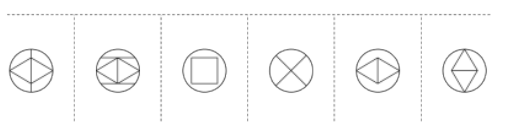

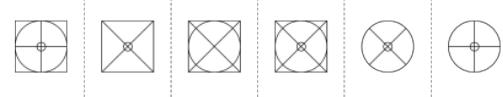

Figure 9. PFS disability goes beyond problems with interpreting syntax and grammar. This is the disability of one of the mechanisms of top-down imagination. Nonverbal tasks requiring imagining a novel combination of two or more objects is impossible in this condition. Typical IQ test tasks involving PFS of several objects: (A) requires the combination of two objects. The top two rows of the matrix indicate the rule: "the object in the right column is the result of the combination of the two objects shown in the left and middle row" (the solution in the $5^{\text {th }}$ square). (B) shows a question that relies on the PFS of four objects. (C) shows a question in which PFS of two objects has to be conducted according to the following rule specified in the top row: "the object in the middle column goes on top of the object in the left column" (the solution in the second square). Note related to Figure 8 . When you are ready to be primed by learning the category of the object displayed in Figure 8, please read the following category: a bird. Once the objectNEs in the posterior cortex have been constrained over a single category of objects, the bird displayed in Figure 8 is recognized by most people. If you still cannot recognize the bird, please wait for the Aha! moment or scroll to the legent of Figure 10 to read the type of the bird. 


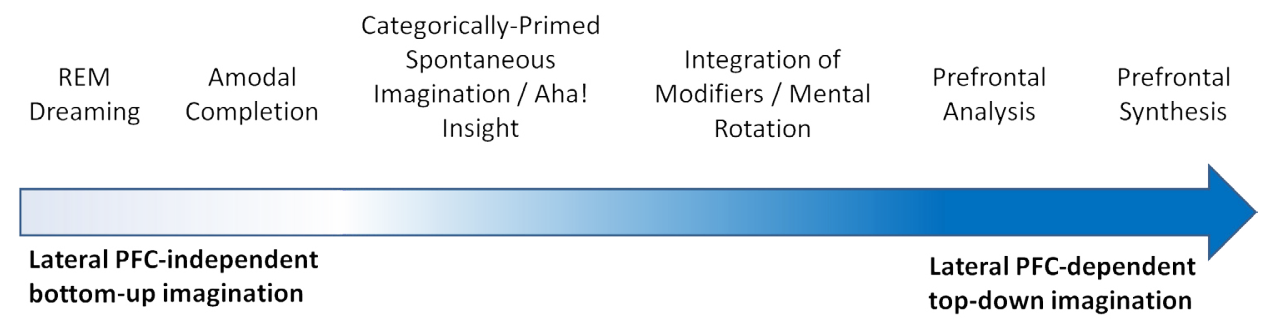

Figure 10. The six different mechanisms of imagination as a function of their dependence on the LPFC.

Note related to Figure 8 . The bird displayed in Figure 8 is an eagle.

but PFS is not necessary for using an object as a symbol. For example, the use of red ochre may be highly symbolic due to its association with blood. However, this association may be entirely based on memory of an emotional event such as a bloody battle, as well as spontaneously formed imagery of a battle. Crucially, memory recall and spontaneously formed imagery (like in a dream or during an insight) do not rely on PFS and therefore use of red ochre is not an indication of the PFS abilities in hominins. Similarly, simple personal ornaments such as perforated shells $[45,48-50]$ could have been used as symbols of social power. However, neither their manufacturing nor use signify the PFS ability. The line marks on stones and shells [51], as well as geometrical figures and hand stencils painted on cave walls are undoubtedly associated with general improvement in the LPFC function and active imagination in their creators, but there is nothing in these artifacts indicating the presence of the most advanced component of active imagination, the PFS ability.

The first definitive evidence of PFS appears in the archeological record around 65,000 to 40,000 and it emerges simultaneously in several modalities: 1) composite figurative arts, 2) manufacturing of multitude of new types of tools, 3) improvements in design and construction of living quarters, and 4) elaborate burials. Together with 5) fast colonization of the globe and migration to Australia (presumably by boats) at around 62,000 years ago and 6) demise of the Pleistocene megafauna (presumably with the aid of animal traps) the archeological evidence indicates the presence of PFS ability in hominins by about 65,000 years ago (ya).

1. Composite figurative objects. Depiction of composite objects that don't exist in nature provides an undeniable evidence of PFS. These composite objects such as the Lowenmensch ("lion-man") sculpture from the caves of Lone valley in Germany (dated to 37,000 ya, Figure 11) [52] must have been imagined by the artists by first mentally synthesizing parts of the man and beast together and then executing the product of this mental creation in ivory or other materials. The composite artworks such as lion-man from Germany, a bird-man from Lascaux, a lion-woman from Chauvet, and the engraving of a bird-horseman from Hornos de la Peña provide a direct evidence that by 37,000 ya humans were capable of PFS.

2. Innovation. The hominin propensity for innovation can be inferred by looking at the number and quality of the different types of tools they manufactured. Researchers have been able to observe and record an extensive list of over thirty types of tools used in the wild by chimpanzees [53-55]. Most tools, such as stones used to break nuts, are used in their natural form, but there are a few tools that are manufactured by chimpanzees. For example, chimps prepare sticks for termite-fishing by trimming twigs; they also make a sort of spear for hunting bushbabies by biting on one end of a stick [56]. Hominins gradually expanded on the chimpanzee repertoire by adding stone tools of increasing sophistication [46] from 3.3 million ya [57] as well as wooden spears from 400,000 ya [58]. In the absence of PFS, however, any innovation has to come through a spontaneous insight or trial-and-error, that are random and therefore slow processes. PFS, on the other hand, allows one to mentally simulate all the possible solutions to a problem, select the best solution and then mentally test multiple manufacturing processes. In comparison to the relative stasis of tool development by early hominins, tool development by modern humans seems to be lightning fast $[59,60]$. As early as 64,000 ya humans introduced quartz-tipped arrows suggesting the development of the bow-and-arrow [61]; bone needles $(61,000$ ya) [62], musical instruments - tools for facilitating the process of producing pleasing sounds (43,000 ya) [63], and ceramic technology (31,000 ya) [64]. The explosion of these different kinds of manufactures tools within a short period of time between 65,000 and 40,000 ya is consistent with PFS acquisition.

3. Design and construction. Human dwellings are not built by reflex or insight, an integral part of construction is mental design of the structure in the process of PFS. There is little evidence of hominins constructing dwellings or fire hearths until the arrival of Homo sapiens. While Neanderthals controlled the use of fire, their hearths were usually very simple: most were just shallow depressions in the ground. There is almost a complete lack of evidence of any dwelling construction during this period [65]. The arrival of Homo sapiens, on the other hand, is marked by a multitude of constructed structures including stone-lined and dug-out fireplaces, as well as unambiguous remains of dwellings, which all flourished starting around 30,000 ya. These include foundations for circular hut structures at VigneBrune in eastern France, dating to 27,000 ya [66]; postholes and pit clusters at a site near the village of Dolní Věstonice in the Czech Republic, dating to 26,000 ya [67], and mammoth bone structures at Kostienki, Russia, and Mezirich, Ukraine [68]. As early as 12,000 ya, Homo sapiens introduced agriculture and 

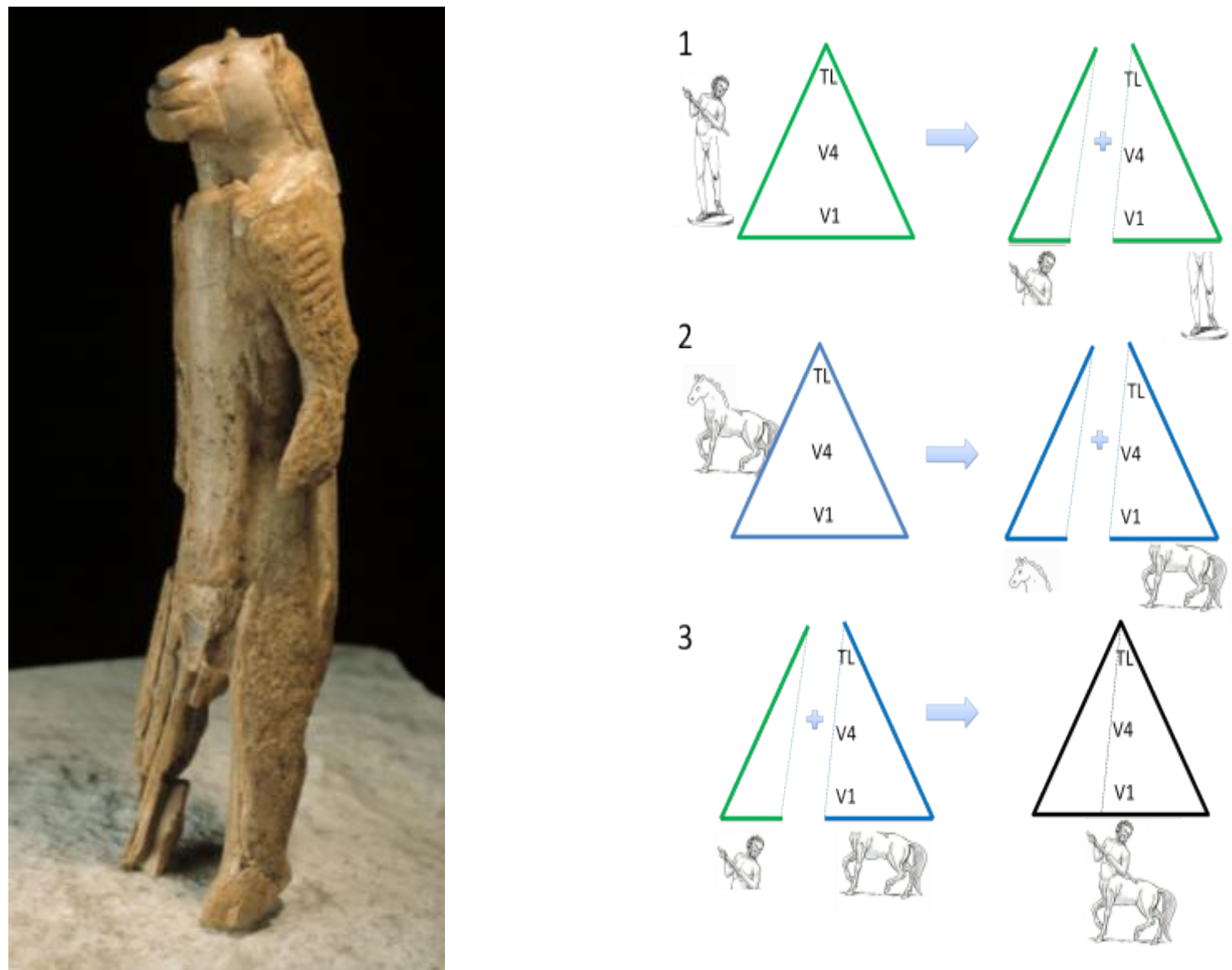

Figure 11. (A) "Lion-man", statuette carved of mammouth-tusk, Site: Hohlenstein-Stadel-cave, Germany, dated to 37,000 years ago (ya), Inv. Ulmer Museum Prä Slg. Wetzel Ho-St. 39/88. Photo Thomas Stephan (C) Ulmer Museum, Ulm, Germany. (B) The neurological process of constructing a new composite mental image, such as centaur, involves (1) segmenting a man's objectNE, (2) segmenting a horse objectNE, and (3) synthesis of man's head objectNE and horse's body into a new objectNE.

started to build permanent villages [59,60]. The appearance of well-planned dwellings as well as stone-lined and dug-out fireplaces is consistent with PFS acquisition before 30,000 ya.

4. Adorned burials and religious beliefs. Religious beliefs and beliefs in afterlife are the ultimate products of PFS. Individuals with no PFS ability cannot be induced into believing in Gods, as they cannot comprehend the scriptures or any other religious doctrine. Nor can they understand any mythology, as they cannot imagine cyclops, mermaids, and other mythological creatures. Thus, presence of religious beliefs in a society provides another unambiguous testimony of PFS abilities. The origin of religious beliefs can be traced by following the beliefs in the afterlife. Beliefs in the afterlife, in turn, are often associated with adorned burials. Some of the oldest known human burial, dated at 500,000 ya and attributed to Homo heidelbergensis, was found in the Sima de los Huesos site in Atapuerca, Spain, and consists of various corpses deposited in a vertical shaft [69]. A significant number of burials are also associated with Neanderthals: La Chapelle-aux-Saints, La Ferrassie, and SaintCesaire in France; Teshik-Tash in Uzbekistan; Shanidar Cave in Iraq [70]. However, whether or not these sites constitute actual burial sites is hotly disputed. Their preservation could well be explained by natural depositions [71]. Even if those burials were made deliberately, the goal may have been to simply toss the bodies away in order to discourage hyena intrusion into the caves [59]. In any case, these early burials completely lack the "grave goods" that would indicate the belief in an afterlife [59].

Human skeletal remains that were intentionally stained with red ochre were discovered in the Skhul and Qafzeh caves, in Levant and dated to approximately 100,000 ya [72]. One of the burials contains a skeleton with a mandible of a wild boar, another contains a woman with a small child at her feet, and yet another one containing a young man with a possible offering of deer antlers and red ochre [73]. While these burials are clearly intentional, whether or not they indicate the belief in an afterlife is uncertain. The ochre by itself is an inconclusive evidence. For example, ochre could have been used during lifetime to protect skin from insects [74] and the deceased could have been buried still bearing the ochre marks. The small number of "grave good" found in these burial sites may have simply been objects that fell into the burial pit accidentally. In any case, there is not enough conclusive evidence from these early burials to judge the occupants' beliefs in an afterlife. 
The number of known adorned burials and the sophistication of the offerings significantly increase around 40,000 years ago. To date, over one hundred graves of Homo sapiens have been discovered that date back to the period between 42,000 and 20,000 ya [75]. In many cases several bodies were interred in a single grave. Burial offerings were commonplace and ochre was used abundantly. Examples include: a burial in Lake Mungo, Australia of a man sprinkled with red ochre, dating back to 42,000 ya [76]; an elaborate burial in Sungir, Russia that includes two juveniles and an adult male wearing a tunic adorned with beads and carefully interred with an astonishing variety of decorative and useful objects, dating back to 30,000 ya (Figure 12) [77]; a grave in Grimaldi, Italy, which contains the remains of a man and two adolescents along with burial offerings from around 40,000 ya [75]; and a site in Dolni Vestonice, in the Czech Republic where a woman was buried between two men and all three skulls were covered in ochre dating back to 28,000 ya [78]. The appearance of adorned burials in multiple geographical locations is consistent with acquisition of PFS around 40,000 ya [75].

5. Fast colonization of the globe and migration to Australia. Hominins diffusing out of Africa had been colonizing the Europe and Asia long before the arrival of Homo sapiens: the remains of Homo erectus have been found as far as in Spain [79] and Indonesia [80] and Neanderthals remains have been found in Europe and Asia [81]. However, both the extent and the speed of colonization of the planet by Homo sapiens around 65,000 ya are unprecedented. Our ancestors diffusing out of Africa quickly settled Europe and Asia and crossed open water to Andaman Islands in the Indian Ocean some 65,000 ya [82] and Australia as early as 62,000 ya [83]. Migration to Australia is consistent with the use of boats by early modern humans further underlying their unmatched propensity for technological innovations.

6. Building animal traps and demise of the Pleistocene megafauna. Without PFS one cannot think through the building of an animal trap. An animal trap, such as pitfall trap, requires digging a deep pit and camouflaging it with twigs and branches, so that an unwitting animal would fall right in. PFS aids trap

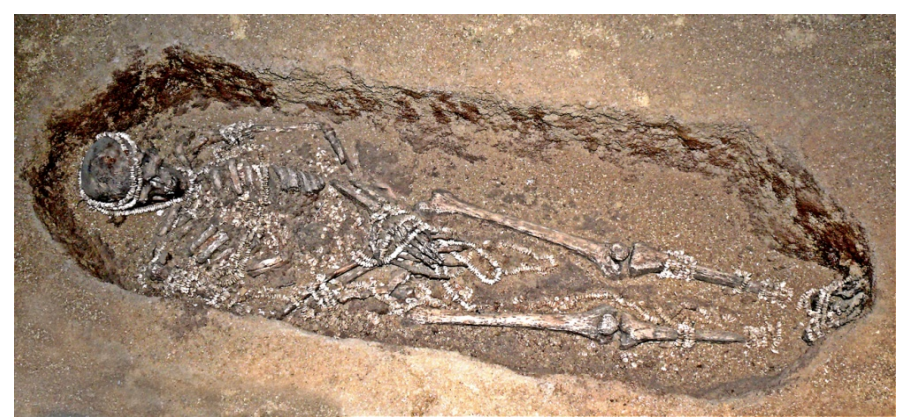

Figure 12. An elaborate burial of a 60-year-old found in Sungir, Russia. The man is wearing bracelets, necklaces, pendants, and a tunic adorned with thousands of mammoth-ivory beads. Two juvenile burials were found at the same site. The site and the skeletons date back to 30,000 ya [77]. Photo JoséManuel Benito Álvarez [Public domain]. building in three ways. First, a leader can use PFS to mentally simulate multiple ways to build a trap. Second, a leader could use PFS to think through the step-by-step process of building a trap. Finally, a leader could communicate the plan to the tribe: "We will make a trap by digging a large pit and covering it with tree branches. A mammoth will then fall into the pit; no need to attack a mammoth head on." In fact, early modern humans are known for building traps; traps for herding gazelle, ibex, wild asses and other large animals were found in the deserts of the Near East [84]. Funnel-shaped traps comprising two long stone walls (up to $60 \mathrm{~km}$ in length!) converged on an enclosure at the apex. Animals were probably herded into the funnel until they reached the enclosure at the apex surrounded by pits, at which point the animals were trapped and killed. Some traps date back to as early as the 7th millennium BC [84].

The correlation of human migration with demise of the Pleistocene megafauna $[85,86]$ is consistent with PFS acquisition that would have enabled mental planning of sophisticated attack strategies with the use of animal traps [84].

Conclusions from paleontological evidence. There is no evidence of PFS ability in hominins before 65,000 ya and there is an abundance of clear and unambiguous evidence of PFS ability in hominins after around 62,000 ya. Composite objects executed in bone and in paintings, explosion of creativity and innovation, construction of dwellings, appearance of adorned burials, and fast colonization of the planet are all the manifestations of PFS. The PFS-related artifacts are highly correlated with each other in time and geography and are associated with Homo sapiens diffusion out of Africa around 65,000 ya. This abrupt change toward behavioral modernity has been characterized by paleoanthropologists as the "Upper Paleolithic Revolution," $[59,87,88]$ the "Cognitive revolution," [89] and the "Great Leap Forward" [90] and it is consistent with acquisition of PFS sometime shortly before 65,000 ya (for a more skeptical position, see Ref. [47]. Remember, however, that researchers arguing for a more gradual cultural and technological elaboration do not differentiate between 'symbolic artifacts' and 'PFS artifacts.' There is no doubt that accretion of symbolic artifacts is gradual. It is the appearance of PFS evidence that seems to be abrupt).

Acquisition of PFS ability increases competitive advantage of a tribe in many ways. First, by changing hunting strategy from persistence hunting to building traps, hominins could have obtained nearly unlimited quantity of food resulting in increased fertility and decreased mortality. Second, tribe's losses to predation must have come down since hominins no longer had to expose themselves to predators during persistence hunting and foraging [91]. Third, the number of wounds received in close combat with large animals had to come down as a result of preferential use of trapping of megafauna. Fourth, PFS must have dramatically increased cohesion between tribe members through religion and syntactic language [92]. Fifth, PFS facilitated the process of discovery of new tools, such as spear throwers and bow-and-arrows [61]. Thus, it is likely that a tribe 
that first acquired PFS would have quickly increased in size and overcome the rest of hominins. The genetic bottleneck that has been detected around 70,000 [93] may have been associated with "founder effect" of such a tribe that acquired PFS and consequently developed a significant competitive advantage over the rest of hominins and other animals.

Prefrontal Analysis acquisition: PFA acquisition in hominines can be followed by looking at the stone tools culture. Turning an unformed stone into a sharp tool requires hitting the stone at just the right angle and in just the right location. According to Ian Tattersall, "To make a carefully shaped handaxe from a lump of rock not only demanded a sophisticated appreciation of how stone can be fashioned by fracture, but a mental template in the mind of the toolmaker that determined the eventual form of the tool" [59]. In neurological terms, this "mental template" is an objectNE encoding the future chopper. Crucially, this objectNE is different from the objectNE encoding the original cobblestone. In other words, the mental template was not recalled from memory but must have been imagined by voluntarily reducing the objectNE of the original cobblestone.

Apes do not manufacture stone tools in the wild and attempts to teach stone tools manufacturing to apes have failed [94], suggesting apes are not capable of forming a mental template and that PFA was acquired after humans have split from chimpanzee line 6 million ya. The first stone tools, Mode One stone choppers, are dated to about 3.3 [57] to 2.5 [95] million ya. These Mode One choppers are crude, asymmetrical, and cannot be re-sharpened, Figure 13. Starting from about 2 million ya, hominins were capable of manufacturing fine symmetrical Mode Two handaxes that could be easily re-sharpened [46]. If the quality of stone tools is informing us of the quality of mental template and the corresponding LPFC ability to mold their percept into the mental template, then stone tools provide a time record of improving LPFC function. Specifically, the succeeding hominin species were exhibiting consistently better voluntary control of their PFA, Figure 13.

Integration of modifiers and mental rotation: The time of acquisition of integration of modifiers and mental rotation is harder to determine as archeological markers are absent. Although mental rotation has been demonstrated in baboons [96,97], rhesus monkey [98], and sea lion [99], the latest experimental data question the assumption that animals use the same flexible neurological mechanism as humans [100]. It is likely that acquisition of integration of modifiers coincided with acquisition of speech around 2 million to 600,000 ya $[92,101]$. Acquisition of speech could have also facilitated the acquisition of mental rotation by the LPFC as the following data from modern deaf individuals unequivocally show. Greater and earlier use of signs for directions by deaf individuals are associated with better mental rotation capabilities: 1) Deaf individuals who had learned American Sign Language (ASL)

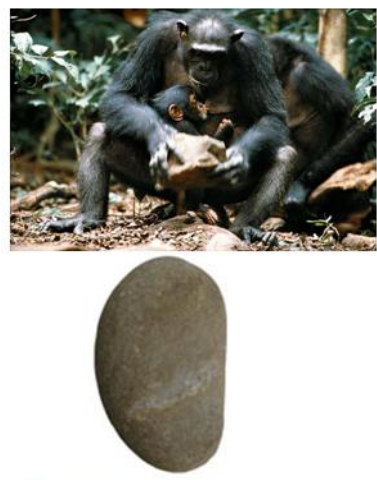

Chimpanzee

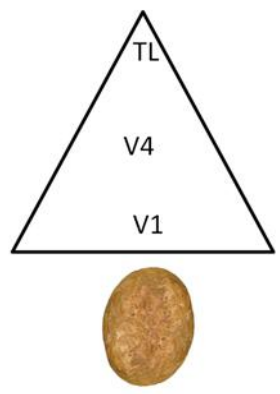

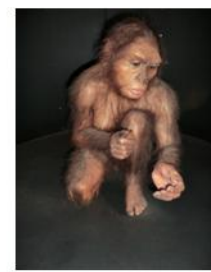

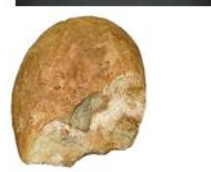

Homo habilis: Mode One tools

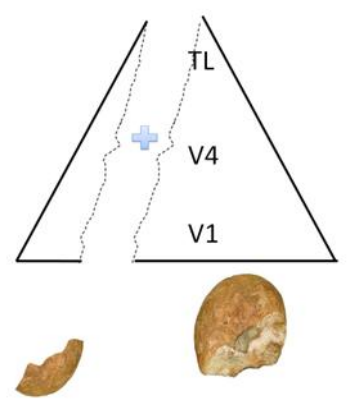

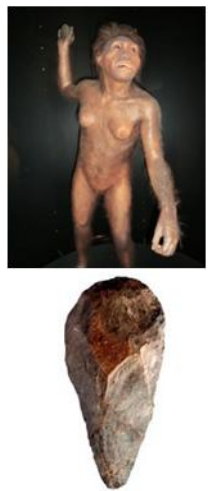

Homo erectus:

Mode Two tools

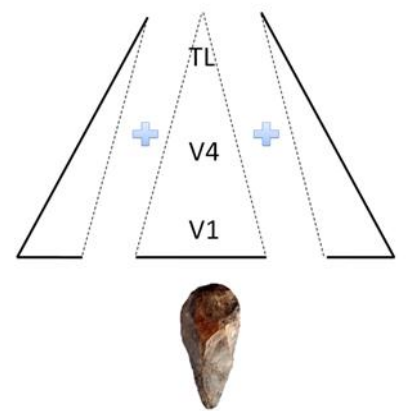

Figure 13. Evolution of Prefrontal Analysis and the corresponding stone tool culture. Chimpanzees make use of cobbles to break nuts but they do not modify them. Homo habilis was one of the earliest hominin species that intentionally modified cobbles to manufacture the crude, Mode One choppers. Homo habilis was only able to break out large flakes from a cobble; its voluntarily control of its mental template was quite crude: it was only capable of desynchronizing large chunks of objectNEs. Homo erectus, on the other hand, was able to break off much smaller flakes and produce the fine, symmetrical, Mode Two handaxes; therefore, Homo erectus was most likely capable of finer voluntary control of its mental template. 
early in life were found to be more accurate than later learners at identifying whether two complex-shape figures presented at different degrees of rotation were identical or mirror images of each other [102]. 2) Individuals who learned ASL earlier were also faster than later learners at identifying whether two-dimensional body-shaped figures (bears with one paw raised) presented at different rotations were identical or mirror images of each other [103]. 3) Even after decades of signing experience, the signers who learned ASL earlier were better at mental rotation accuracy despite greater number of years of experience with the language [104]. 4) Among deaf individuals who acquire sign language at the same age, richness of "spatial" language makes a difference. First cohort of signers acquired the emerging sign language in Nicaragua when this language was just invented and had few spatial prepositions, while the second cohort of signers acquired the language in a more complex form with more spatial prepositions. Predictably, the second cohort of signers (tested when they were in their 20s), who used language with greater number of spatial prepositions outperformed the first cohort of signers (tested when they were in their 30s) in several mental rotation tasks [105].

\section{Bottom-up mechanisms of imagination}

REM sleep dreaming in animals: REM sleep has evolved separately in mammals and birds (in birds, many traits have evolved independently from mammals, such as bipedalism, thermoregulation, vocal communication, etc.). In mammals, periods of REM sleep have been observed in marsupials and placentals but not in the monotremes (monotremes were the first egg-laying mammals to develop from reptiles) [106]. The absence of REM sleep in the echidna suggests that this stage of the sleep cycle evolved some 140 million ya, when marsupials and placentals diverged from the monotreme line. Since REM sleep in humans is associated with vivid dreaming, it was hypothesized that animals could experience similar incidence of dreaming during REM [107]. Animals, however, cannot describe their mental experiences verbally. Indirect experimental investigation of dreaming in animals included several techniques. The first technique involved disabling REM paralysis. When neurons in the brainstem that keep an animal from moving during REM sleep are disabled, many animals behave in a way that makes them look like they are acting out their dreams [108] very much like humans with REM sleep behavior disorder [109]. For example, researchers found that sleeping cats rose up and attacked or were startled by invisible objectsostensibly images from dreams [108]. By itself this observation is not informing on an animal's novel subjective experience as an animal could simply re-play an earlier experience stored in memory. We, however, are interested in the imaginative aspect of dreaming and, therefore, we are only interested in novel mental experiences. A second technique developed by Freyja Ólafsdóttir and explained in Figure 14, comes closer to our aim as it involves recording neuronal "preplay" of events that never happened with an animal (visiting the inaccessible rewardcontaining arm of the track) and therefore provides an evidence of an animal's forming a novel experience in their mind [110].

One day recording from rats' posterior hot zone could tell us more about the richness of the rat's sensory experience. Until then, drawing a connection between the rat's simulation of visiting the inaccessible reward-containing arm of the track to humans' REM sleep dreaming is a speculation, but if, in fact, rats are perceiving novel experiences during REM sleep, then dreaming imagination must have evolved before the rodent line split from primates line some 100 million ya. In this case, it is likely that just like in humans, objectNEs get spontaneously activated during REM sleep creating a way for all mammals (excluding monotremes) to simulate future experiences and

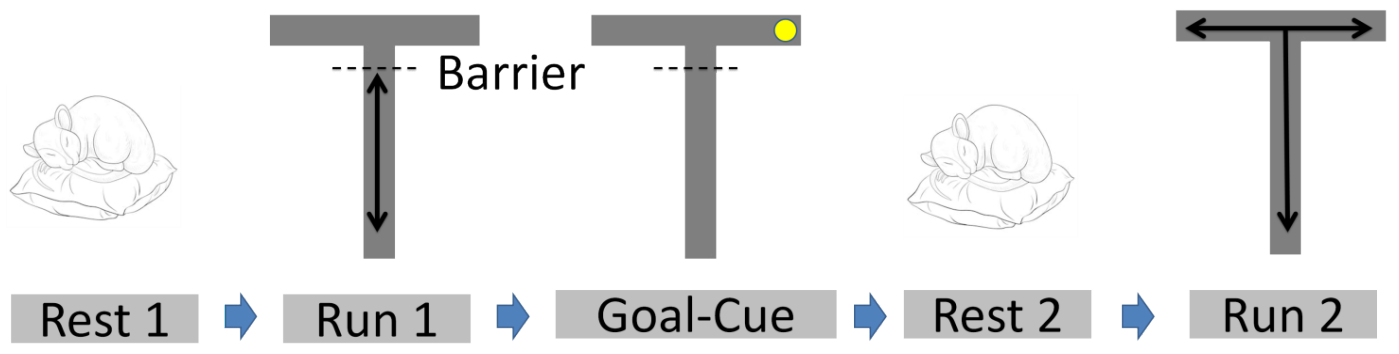

Figure 14. Formation of a novel experience in an animal during sleep. The technique developed by Freyja Ólafsdóttir and colleagues involves recording neuronal "preplay" of events that never happened with an animal and therefore provides an evidence of an animal's forming a novel experience in their mind [110]. Hippocampal place neurons encode the location of an animal in space. When the animal is in one location, a few neurons fire, when the animal moves to a new spot, other place neurons fire instead. Each time the animal returns to the same spot, the same place neurons fire. Thus, as the animal moves, a place-specific pattern of firing emerges which can be used to reconstruct the animal's position. By the same token when the animal is not moving, but the place neurons are firing, their placespecific firing pattern can be used to reconstruct the animal's mental experience. In Ólafsdottir experiment, rats were allowed to run up to the junction in a T-shaped track. The animals could see into each of the two arms, but not enter them. Food was then placed in one of the arms, therefore making this arm of the track important for the animal. Will the animal "dream" of visiting this arm of the track during sleep?

Researchers recorded the firing of place neurons when animals were on the track and during sleep afterwards. After the sleep, the rats were allowed to return to the track and enter both arms, and again their brain activity was recorded. Now that researchers knew the place neurons firing pattern corresponding to both arms of the track, they could compare those patterns to the place neurons firing during sleep. Researchers report that in the sleep period after the rats first viewed the inaccessible arms, the place neurons pattern that would later form the mental map of a journey to the food-containing arm was in fact activated. The place neurons pattern that would become the mental map of the other inaccessible arm was not activated. An implication of these findings is that the brain was able to simulate future experience. Furthermore, the brain preferentially simulated the experiences that was functionally significant, since that experience was associated with reward [110]. 
identify best solutions for their problems - the method that in humans is called an insight.

Amodal completion: Amodal completion was observed in mice [111], primates [112], and some bird species [17] suggesting that the phenomenon has evolved separately in mammals and birds.

Categorically-primed spontaneous imagination: Insights and the ensuing "seeing" the complete solution in the mind's eye have been hypothesized to explain novel animal behavior [113], such as Wolfgang Köhler's experiments in which chimpanzees used tools to retrieve a banana by picking up a stick and using it as a rake [114], the experiment in which an elephant reaches the apple by pushing a box into position underneath and standing on it [115], as well as many other observations of problem-solving by apes [116,117], pigeons [118], and ravens [119].

The acquisition of the LPFC by primates [5,120], who split from other mammals around 70 million ya, may have significantly facilitated this semi-spontaneous mechanism of imagination. One of the function of the LPFC is encoding objects' categorical information [32]. From the theoretical perspective, the increased number of object's categories is expected to allow LPFC to fine-tune the categories of primed objectNEs, and, therefore, facilitate finding an insight solution, resulting in faster problem-solving and better adaptive behavior. We could expect somewhat different categorically-primed spontaneous imagination abilities in different primate species and probably even in different individuals resulting in variations of thinking time before arriving to an insight and implementing the solution, which is currently the active area of research by the burgeoning field of comparative cognition.

\section{Conclusions}

Evolution of imagination seems to be related to the evolution of the neocortex in general and the LPFC in particular. Using REM sleep as a marker for dreaming, the spontaneous bottomup imagination of dreaming has evolved in mammals after marsupials and placentals split from monotremes around 140 million ya. Bottom-up spontaneous imagination must have been further facilitated by acquisition of the LPFC by primates around 70 million ya. Top-down active imagination have improved in hominins with PFA acquisition around 3.3 million ya when hominins acquired ability to form mental template and stone tools manufacturing has ensued. The ability of the LPFC to modify mental image significantly improved in hominins over time as can be observed in improving quality of stone tools and climaxed with the acquisition of PFS just 70,000 ya, Figure 15.

\section{Imagination Acquisition by Children}

\section{Top-down mechanisms imagination}

Prefrontal synthesis: Our group have investigated acquisition of PFS in children using Linguistic Evaluation of PFS (LEPS) test, that utilizes the simplest possible language- based tasks to assess the PFS ability [121]. The test includes flexible syntax and language recursive elements, such as spatial prepositions, to present participants with a set of novel questions that participants have never encountered before (new questions are essential in order to exclude answering from memory). LEMS items include puzzles with tangible objects, such as: 'Put the green cup inside the blue cup;' 'Show me: the giraffe ate the elephant;' 'Put the giraffe under the monkey;' as well as abstract questions, such as: 'Imagine a chicken and a cow. Which one is bigger?;' 'If a monkey ate a lion, which one is still alive?;' 'Imagine the red cup inside the green cup, which cup is at the bottom?'

We have found that children acquire PFS between ages of 3 and 4. There was no evidence of PFS before the age of 3 and most children older than 4 were able to answer most LEMS items correctly.

Prefrontal analysis: We have attempted to study PFA in young children by asking them to form a piece of clay into a circle, square, or triangle. The results were highly ambiguous and mainly depended on a child's fine motor control abilities. This effort was abandoned.

Integration of modifiers and mental rotation: Integration of modifiers is easier than PFS. Most three-year-old children in our tests were capable of following a direction to find a long red straw among many straws of different sizes and colors, as well as other objects, but no three-year-old was able to answer more than $30 \%$ of PFS questions [121]. Note the mechanism of mental integration of a modifier with an object per examiner's description is different from the child's ability to name the size and color of an object chosen by the child herself which is usually observed around the age of 2.5.

Mental rotation ability also significantly improves around the age of three. The number of children answering above chance in the three-dimensional mental rotation task increases from $10 \%$ of three-year-olds to $95 \%$ of 5 -year-olds [122].

\section{Bottom-up mechanisms of imagination}

Dreaming: The amount of REM sleep peaks in the third trimester of gestation [123] and decreases after birth. An important caveat discussed above is that we can only talk about a correlation between dreaming and REM sleep. The presence of REM sleep, however, is the best marker of dreaming we have and, as soon as children start talking, around the age of 2 , they sometimes report vivid dreams (usually nightmares) experienced during sleep [124,125].

Amodal completion: Depending on details of procedure, infants show evidence of amodal completion at about 4-7 months of age [126].

Categorically-primed spontaneous imagination: The development of categorically-primed spontaneous imagination in children can be followed through pretend play and stories spontaneously recounted by children who start talking early. Both phenomena occur universally across all cultures and begin unprompted between the ages of 1.5 to 2 [127]. 


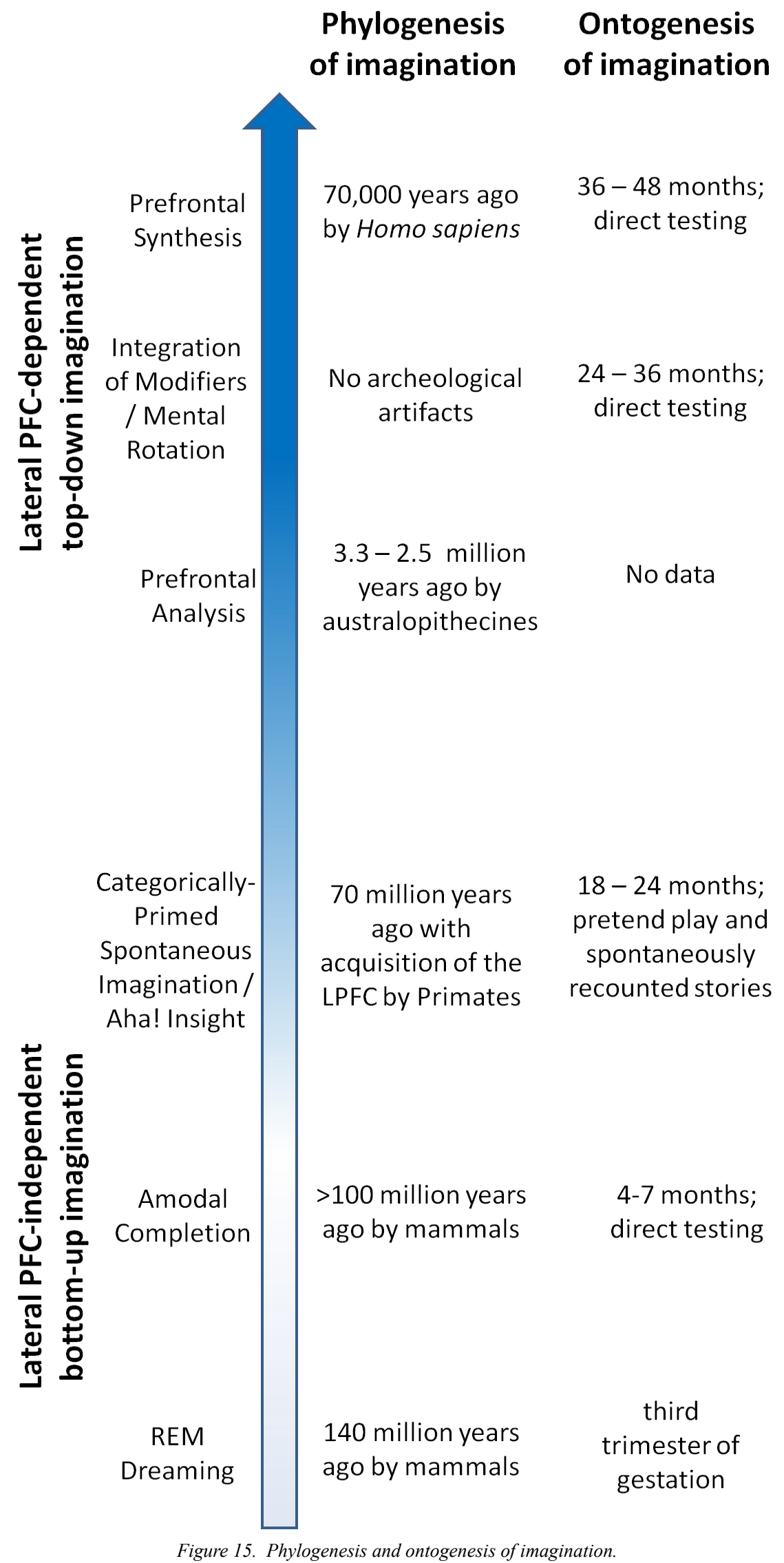

Figure 15. Phylogenesis and ontogenesis of imagination. 


\section{Conclusions}

In ontogenesis, just as in phylogenesis, bottom-up imagination manifests before top-down LPFC-driven mechanisms of imagination, Figure 15.

\section{Discussion}

The current definition of imagination is too simple and ambiguous, and hinders the progress of evolutionary and developmental neuroscience. This definition did not change for thousands of years and left a lot of great thinkers confused about subjective mental processes in humans and animals. For example, Charles Darwin did not distinguish imagination used for reasoning (i.e. PFS) from dreaming hallucinations. In the same paragraph Darwin uses both PFS and dreaming as examples of imagination: "The imagination is one of the highest prerogatives of man. By this faculty he unites former images and ideas, ... and thus creates brilliant and novel results... Dreaming gives us the best notion of this power..." [128]. Darwin's writings clearly show why it is dangerous and counterproductive to swipe all imaginary experiences under a single phenomenon of imagination. Darwin argues that since most mammals dream, they must all possess imagination implying the ability of PFS: "As dogs, cats, horses, and probably all the higher animals, even birds have vivid dreams, and this is shewn by their movements and the sounds uttered, we must admit that they possess some power of imagination" [128]. While dogs, cats, and horses might very well conjure up novel images in their dreams, the mechanism of their bottom-up spontaneous imagination is diametrically different from the topdown imagination associated with human purposeful mental simulations in the process of PFS.

To our knowledge, the first scientist to suggest a difference in the neurobiology of two main mechanisms of imagination - the LPFC-driven top-down and the LPFC-independent spontaneous bottom-up mechanism - was Ivan Pavlov. Nearly 80 years ago Pavlov was writing: "Life definitely reveals two categories of people - artists and thinkers. ... In the artist the activity of the cerebral hemispheres flowing through the whole mass, involve least of all the frontal lobes, concentrating chiefly on the remaining parts; in the thinkers, however, the converse is true" [129].

The notion about a special type of imagination, different from dreaming and spontaneous insight, which is possibly unique to humans has been entertained by many modern scientists. Ian Tattersall, writes “... if there is one single thing that distinguishes humans from other life-forms, living or extinct, it is the capacity for symbolic thought: the ability to generate complex mental symbols and to manipulate them into new combinations. This is the very foundation of imagination and creativity: of the unique ability of humans to create a world in the mind..." [59]. Lev Vygotsky argues that "Imagination is a new formation that is not present in the consciousness of the very young child, is totally absent in animals, and represents a specifically human form of conscious activity" [130]. Joseph Carroll writes "the modern human mind, alone among all minds in the animal kingdom ... is free to organize the elements of its perception in an infinitely diverse array of combinatorial possibilities" [131]. Clearly, Tattersall, Vygotsky, and Carroll are not talking about spontaneous bottom-up imagination, but describe the active purposeful process of PFS.

PFS-like abilities were also defined descriptively as "ability to invent fiction" [132], "episodic future thinking" [133], "mental scenario building" [134], "mental storytelling" [135], "internal mentation" [136], "mentally playing with ideas" [137], "memory of the future" [138], "counterfactual thinking" [139], "integration of multiple relations between mental representations" [43], "the ability to form nested scenarios" [140]. The neurobiologically-explicit definitions of top-down mechanisms of imagination avoid ambiguity of descriptive definitions and allow precise analysis of neurobiological bases of behaviors associated with the presence or absence of specific imaginative abilities.

In this manuscript we described six mechanisms of constructive imagination. Each mechanism results in a novel image appearing in the mind's eye. The six mechanisms do not cover all the neurobiologically diverse mechanisms of constructive imagination, but they are a place to start. From the most spontaneous/least voluntary to the most voluntary, the six mechanisms of imagination include dreaming hallucinations, amodal completion, categorically-primed spontaneous imagination, integration of modifiers and mental rotation, PFA, and PFS (Figure 10). Other types of imagination, such as daydreaming and lucid dreaming, were omitted because they likely represent a mixture between REM sleep dreaming and waking PFS: the PFC is more active than in dreaming, but imagery is primarily driven by spontaneous activity in the posterior cortex, just like in REM dreaming [141].

\section{Evolution of imagination}

Once the components of imagination were defined, we attempted to map them onto phylogenetic and ontogenetic development. Predictably, the most spontaneous/least voluntary bottom-up mechanisms of imagination, that minimally rely on the LPFC, are phylogenetically oldest and ontogenetically first to develop, Figure 15.

REM sleep dreaming was likely acquired by mammals some 140 million ya, when marsupials and placentals diverged from the monotreme line. Children likely experience REM sleep dreaming as early as the third trimester of gestation [123]. Another bottom-up mechanism of imagination, amodal completion, has probably also been acquired early in mammalian evolution as it has been observed in mice [111] and primates [112]. Children seem to acquire amodal completion at about 4-7 months of age [126]. Categorically-primed spontaneous imagination has probably improved in primates with the acquisition of the LPFC $[5,120]$ around 70 million ya and 
continued to improve with increasing size of the LPFC in apes and hominins. In children, the development of categoricallyprimed spontaneous imagination can be easily observed via pretend play and spontaneously recounted stories around ages of 1.5 to 2 [127].

All mechanisms of top-down active imagination may have evolved after hominins split from a chimpanzee line around 6 million ya as the ability to flexibly integrate modifiers has not been demonstrated in any animal and mental rotation, that has been demonstrated in animals, may be utilizing a neurobiological mechanism that is different from humans [100]. In children, top-down imagination is clearly exhibited around the age of 3 when they become capable of following a direction to find a long red straw among many straws of different sizes and colors [121]. PFA acquisition by hominins can be easily followed by looking at the stone tools culture that was slowly improving from about 3.3 million ya [57]. The most advanced mechanism of imagination, PFS, was acquired phylogenetically only 70,000 ya [92] and develops in children between ages of 3 and 4 [121].

\section{Top-down imagination acquisition by children with autism}

Top-down imagination is acquired naturally in neurotypical children, but is known to be a common challenge for children with Autism Spectrum Disorder (ASD) [26]. As a consequence, ASD symptoms often include a phenomenon called stimulus overselectivity (a.k.a. tunnel vision, or lack of multi-cue responsivity), whereby an individual cannot mentally combine disparate objects from memory into a novel image [142144]. For instance, s/he will have difficulty accomplishing a seemingly trivial task, such as an instruction to "pick up a blue straw that is under the table," which requires to combine three different features, i.e. the object itself (straw), its color (blue), and its location (under the table). The LPFC must then mentally integrate all of these into a new mental image, a blue straw under the table, in order to take the correct action. When asked to "pick up a blue straw under the table," a child with ASD who is unable to mentally synthesize the straw with its color and location may attend to the word "straw" and ignore both its location and the fact that it should also be blue, therefore picking up any available straw; alternatively, the child can focus on the color, therefore picking up any blue object.

Predictably, children with ASD acquire simpler top-down imagination mechanisms, such as integration of modifiers, more readily than PFS. For example, 17-year-old individual with ASD tested by us, had no problems combining several modifiers with a noun (e.g. 'give me a long red straw'), but failed all PFS questions [121].

The importance of early acquisition of PFS cannot be overstated. The impaired PFS affects virtually every area of an individual's verbal, cognitive and social functioning, including the lack of comprehension of flexible syntax and spatial prepositions [145]. Importantly, unlike many other functions, such as acquisition of vocabulary and grammatical rules, which can be learned throughout one's lifetime, there is only a short critical period for the development of PFS [26]. If this early childhood critical period is missed, a lifelong PFS disability condition sets in. As a result, 30-40\% of individuals diagnosed with ASD experience lifelong impairment of the ability to understand flexible syntax and spatial prepositions [146]. These individuals, commonly referred to as having low-functioning ASD, typically exhibit full-scale IQ below $70[44,147]$ and usually perform below the score of 85 in non-verbal IQ tests [44]. In fact, the PFS ability and the derivative capacity of understanding flexible syntax and spatial prepositions, may be the most salient differentiator between high-functioning and low-functioning ASD.

The ASD medical community is very aware of this early critical period, and there is a wide consensus that intense early intervention should be administered to children as soon as they are diagnosed with ASD [148]. The goals of speech language pathologists (SLP) and Applied Behavioral Analysis (ABA) therapists happen to be built around the construct of top-down imagination, and therefore it is highly targeted in these treatments. SLPs commonly refer to top-down imagination developing techniques as "combining adjectives, location/orientation, color, and size with nouns," "following directions with increasing complexity," and "building the multiple features/clauses in the sentence" [149]. In ABA jargon, these techniques are known as "visual-visual and auditory-visual conditional discrimination" [150-153], “development of multi-cue responsivity" [143], and "reduction of stimulus overselectivity" [144].

Parents, on the other hand, may under-appreciate the importance of exercises for top-down imagination development or over-rely on the outsourced "twice a week" therapy. Ambiguous terminology can also increase parents' confusion, as child's bottom-up creativity (Figure 16) can be easily interpreted as a manifestation of top-down imagination. The observation that children with ASD in Latin America and Southern Europe improve significantly better than children in English-speaking countries [154] confirms a common belief that the outcome can be significantly improved in Englishspeaking children with ASD. For example, even in neurotypical children, greater adult-child conversational experience is related to stronger frontoposterior connections [155] and, presumably, better top-down imagination mediated by these frontoposterior connections [11]. This observation suggests that the development of frontoposterior connections is environmentally influenced by early top-down imagination exercises stimulated by dialogic interaction. It is therefore likely that even in nonverbal children with ASD, top-down imagination acquisition can be stimulated by exercises aimed at training of top-down imagination. One of the main reasons to continue investigating the theoretical basis of different mechanisms of imagination is to develop new practical therapy techniques for children with ASD [156,157]. 

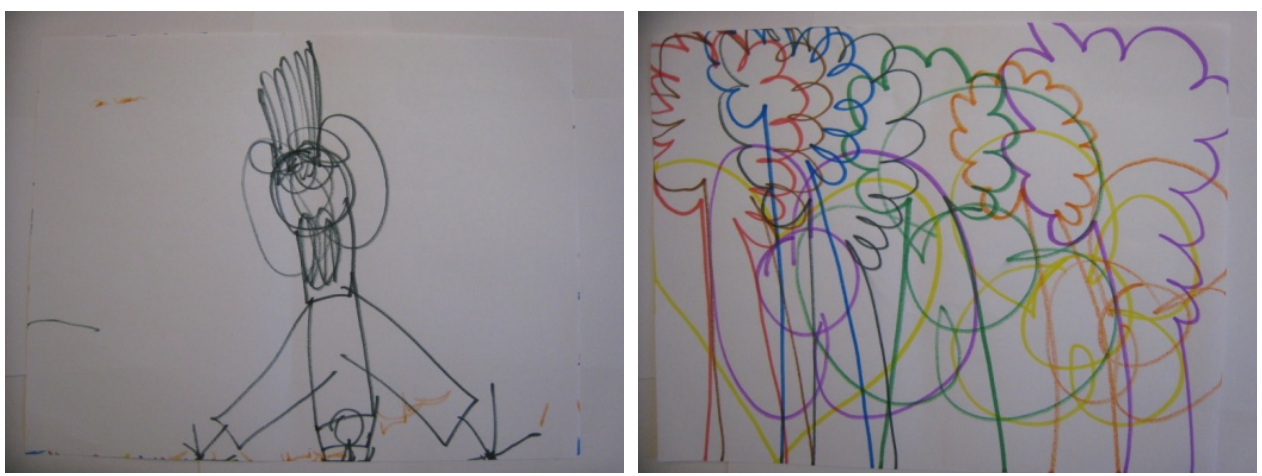

Figure 16. Creativity. Along with imagination, creativity is another term that is often used to describe mental capabilities. Unfortunately, it is as ambiguous as imagination. An autistic savant who is unable to understand flexible syntax and spatial prepositions and shows other hallmarks of PFS disability, can at the same time be highly creative in his/her paintings. This figure shows two drawings by 17-year-old verbal individual with ASD and PFS disability [121]. These two drawings, named 'The man, 'and 'Trees in a park' clearly demonstrate his artistic creativity. Oliver Sacks describes another 21-year-old "autist artist”' individual, named Jose who has been deemed "hopelessly retarded," however, when given Sacks' pocket watch and asked to draw it, he drew the watch in surprising detail [158].

In addition to artistic ability, savants can demonstrate rapid calculation, map making, or musical ability. Oliver Sacks described twin savants who appeared to have an almost supernatural ability to quickly tell if a number is prime [158]. The twins - who were variously diagnosed as autistic, psychotic, or severely retarded - are said to have been able to perceive within minutes whether a 20-digit number was prime. Their inability to do simple addition, their diagnosis of mental retardation, and their IQs of 60 leads one to believe that the twins had PFS disability. Nevertheless, the twins were highly creative in prime numbers identification as well as calendar calculations (given a date far in the future they could quickly tell you what day of the week it would fall on).

Patients with frontal-temporal lobe dementia often show dramatic reduction in PFS ability. In some patients though art and music talent emerge, just as the disease destroys higher brain function [159].

We conclude that creativity is a highly ambiguous term that cannot be even loosely matched to any neurobiological mechanism of imagination. Creativity can be totally based on bottom-up or on top-down imagination. As a result, describing any species of hominins as creative does not significantly contribute to understanding of real neurobiological capabilities of that species.

\section{Conclusions}

Imagination is an umbrella term covering at least six component mechanisms: dreaming hallucinations, amodal completion, categorically-primed spontaneous imagination, integration of modifiers and mental rotation, PFA, and PFS. All of these mechanisms result in new unreal visual experiences and therefore constitute part of imagination, while each mechanism is neurobiologically different. Dreaming is the simplest form of constructive imagination. It is evolutionary oldest way to simulate future in the neocortex. Humans retained this ability but acquired a much more efficient forms of active imagination, such as PFS and PFA. Clearer neurobiological definitions of imagination mechanisms can lead to better scientific communication in evolutionary biology and better educational strategies in children with neurodevelopmental delays.

\section{References}

1. Braun AR, Balkin TJ, Wesenten NJ, Carson RE, Varga M, et al, Regional cerebral blood flow throughout the sleep-wake cycle. Brain. 1997; 120: 1173-1197.

2. Siclari F, Baird B, Perogamvros L, Bernardi G, LaRocque JJ, et al. The neural correlates of dreaming. Nat Neurosci. 2017; 20: 872 (2017).

3. Solms M. The neuropsychology of dreams: A clinico-anatomical study. (L. Erlbaum, 1997).

4. Vyshedskiy, Dunn R. Mental synthesis involves the synchronization of independent neuronal ensembles. Res Ideas Outcomes. 2015; 1: e7642.

5. Striedter GF. Principles of Brain Evolution. (Sinauer Associates, 2004).
6. Hebb DO. The organization of behavior: A neuropsychological approach. (John Wiley \& Sons, 1949).

7. Koch C, Massimini M, Boly M, Tononi G. Neural correlates of consciousness: progress and problems. Nat Rev Neurosci. 2016; 17: 307 .

8. Quiroga RQ, Kreiman G, Koch C, Fried I. Sparse but not 'grandmother-cell'coding in the medial temporal lobe. Trends Cogn Sci. 2008; 12: 87-91.

9. Singer W. Binding by synchrony. Scholarpedia. 2007; 2: 1657 (2007).

10. Singer W, Gray CM. Visual feature integration and the temporal correlation hypothesis. Annu Rev Neurosci. 1995; 18: 555-586.

11. Vyshedskiy, Dunn R, Piryatinsky I. Neurobiological mechanisms for nonverbal IQ tests: implications for instruction of nonverbal children with autism. Res Ideas Outcomes. 2017; 3: e13239.

12. Hipp JF, Engel AK, Siegel M. Oscillatory synchronization in large-scale cortical networks predicts perception. Neuron. 2011; 69: 387-396.

13. Sehatpour P, Molholm S, Schwartz TH, Mahoney JR, Mehta AD, et al. A human intracranial study of long-range oscillatory coherence across a frontal-occipital-hippocampal brain network during visual object processing. Proc Natl Acad Sci. 2008; 105: 4399-4404.

14. Hirabayashi T, Miyashita Y. Dynamically modulated spike correlation in monkey inferior temporal cortex depending on the feature configuration within a whole object. J Neurosci. 2005; 25: 10299-10307.

15. Rodriguez E, George N, Lachaux JP, Martinerie J, Renault B, et al. Perception's shadow: long-distance synchronization of human brain activity. Nature. 1999; 397: 430. 
16. Uhlhaas PJ, Singer W. Neural synchrony in brain disorders: relevance for cognitive dysfunctions and pathophysiology. Neuron. 2006; 52: 155-168.

17. Vallortigara G. Visual cognition and representation in birds and primates in comparative vertebrate cognition. Comparative Vertebrate Cogn. 2004; 257-294.

18. Quian Quiroga R, Kraskov A, Koch C, Fried I. Explicit encoding of multimodal percepts by single neurons in the human brain. Curr Biol. 2009; 19: 1308-1313.

19. Waydo S, Kraskov A, Quian Quiroga R, Fried I, Koch C. Sparse representation in the human medial temporal lobe. J Neurosci. 2006; 26: 10232-10234.

20. Gray CM, König P, Engel AK, Singer W. Oscillatory responses in cat visual cortex exhibit inter-columnar synchronization which reflects global stimulus properties. Nature. 1989; 338: 334-337.

21. Miyashita Y. Cognitive memory: cellular and network machineries and their top-down control. Science. 2004; 306: $435-440$ (2004).

22. Tomita H, Ohbayashi M, Nakahara K, Hasegawa I, Miyashita Y. Top-down signal from prefrontal cortex in executive control of memory retrieval. Nature. 1999; 401: 699.

23. Penfield W, Roberts L. Speech and brain mechanisms. (Princeton: Princeton University Press, 1959).

24. Chomsky N. On phases. Curr Stud Linguist Ser. 2008; 45: 133 (2008).

25. Friederici AD. The brain basis of language processing: from structure to function. Physiol Rev. 2011; 91: 1357-1392.

26. Vyshedskiy A, Mahapatra S, Dunn, R. Linguistically deprived children: meta-analysis of published research underlines the importance of early syntactic language use for normal brain development. Res Ideas Outcomes, 2017; 3: e20696

27. Gabay S, Kalanthroff E, Henik A, Gronau N. Conceptual size representation in ventral visual cortex. Neuropsychologia. 2016; 81: 198-206.

28. Wierzynski CM, Lubenov EV, Gu M, Siapas AG. State-dependent spike-timing relationships between hippocampal and prefrontal circuits during sleep. Neuron. 2009; 6: 587-596.

29. Lewis PA, Knoblich G, Poe G. How memory replay in sleep boosts creative problem-solving. Trends Cogn Sci. 2018; 22: $491-503$ (2018).

30. Hobson R, McCarley J. Theory of Dreaming. 1977.

31. Solms M. Dreaming and REM sleep are controlled by different brain mechanisms. Behav Brain Sci. 2000; 23: 843-850.

32. Sidtis JJ, Volpe BT, Holtzman JD, Wilson DH, Gazzaniga MS. Cognitive interaction after staged callosal section: evidence for transfer of semantic activation. Science. 1981; 212: 344-346.

33. Bowden EM, Jung-Beeman M, Fleck J, Kounios J. New approaches to demystifying insight. Trends Cogn Sci. 2005; 9: 322-328.

34. Sternberg RJ, Davidson JE. The nature of insight. (The MIT Press, 1995).

35. Weisberg RW. Creativity: Understanding innovation in problem solving, science, invention, and the arts. (John Wiley \& Sons, 2006).
36. Salvi C, Bricolo E, Kounios J, Bowden E, Beeman M. Insight solutions are correct more often than analytic solutions. Think Reason. 2016; 22: 443-460.

37. Miller EK, Cohen JD. An integrative theory of prefrontal cortex function. Annu Rev Neurosci. 2001; 24: 167-202.

38. Miller E, Miller EK. Neuron. 2017; 95: 1237.

39. Nir Y, Tononi G. Dreaming and the brain: from phenomenology to neurophysiology. Trends Cogn Sci. 2010; 14: 88-100.

40. Fuster J. The Prefrontal Cortex, Fourth Edition. (Academic Press, 2008).

41. Luria AR. Traumatic aphasia. Mouton. The Hague. 1970.

42. Cole M, Levitin K, Luria AR. The autobiography of Alexander Luria: A dialogue with the making of mind. (Psychology Press, 2014).

43. Waltz, J. A., Knowltan BJ, Holyoak KJ, Boone KB, Mishkin FS, et al. A system for relational reasoning in human prefrontal cortex. Psychol Sci. 1999; 10: 119-125.

44. Boucher J, Mayes A, Bigham S. Memory, language and intellectual ability in low-functioning autism. J Boucher DM Bowler Eds Mem. Autism Camb. CUP (2008).

45. Zilhão, J, Angelucci DE, Badal-García E, d’Errico F, Daniel F, et al. Symbolic use of marine shells and mineral pigments by Iberian Neandertals. Proc Natl Acad Sci. 2010; 107: 1023-1028.

46. Klein RG. The human career: human biological and cultural origins. (University of Chicago Press, 2009).

47. McBrearty S, Brooks AS. The revolution that wasn't: a new interpretation of the origin of modern human behavior. J Hum Evol. 2000; 39: 453-563.

48. Bouzouggar A, Barton N, Vanhaeren M, d'Errico F, Collcutt S, et al. 82,000-year-old shell beads from North Africa and implications for the origins of modern human behavior. Proc Natl Acad Sci. 2007; 104: 9964-9969.

49. Henshilwood C, d'Errico F, Vanhaeren M, van Niekerk K, Jacobs Z. Middle stone age shell beads from South Africa. Science. 2004; 304: 404-404.

50. d'Errico F, Henshilwood C, Vanhaeren M, van Niekerk K. Nassarius kraussianus shell beads from Blombos Cave: evidence for symbolic behaviour in the Middle Stone Age. J Hum Evol. 2005; 48: 3-24.

51. Henshilwood CS, d'Errico F, Watts I. Engraved ochres from the middle stone age levels at Blombos Cave, South Africa. J Hum Evol. 57: 27-47.

52. Dalton R. Lion man takes pride of place as oldest statue. (Nature Publishing Group, 2003).

53. van Lawick-Goodall J. The behaviour of free-living chimpanzees in the Gombe Stream Reserve. Anim Behav Monogr. 1968; 1: 161IN1-311IN12.

54. McGrew WC. Chimpanzee material culture: implications for human evolution. (Cambridge University Press, 1992).

55. Whiten A, Goodall J, McGrew WC, Nishida T, Reynolds V, et al. Cultures in chimpanzees. Nature. 1999; 399: 682-685. 
56. Pruetz JD, Bertolani P. Savanna chimpanzees, Pan troglodytes verus, hunt with tools. Curr Biol. 2007; 17: 412-417.

57. Harmand S, Lewis JE, Feibel CS, Lepre CJ, Prat S, et al. 3.3-million-year-old stone tools from Lomekwi 3, West Turkana, Kenya. Nature. 2015; 521: 310-315.

58. Oakley KP, Andrews P, Keeley LH, Clark JD. A reappraisal of the Clacton spearpoint. in Proceedings of the Prehistoric Society 43, 13-30 (Cambridge University Press, 1977).

59. Tattersall I. Becoming human: Evolution and human uniqueness. (Houghton Mifflin Harcourt, 1999).

60. McClellan III JE, Dorn H. Science and technology in world history: an introduction. (JHU Press, 2015).

61. Lombard M. Quartz-tipped arrows older than $60 \mathrm{ka}$ : further usetrace evidence from Sibudu, KwaZulu-Natal, South Africa. J Archaeol Sci. 2011; 38: 1918-1930.

62. Backwell L, d'Errico F, Wadley L. Middle stone age bone tools from the Howiesons Poort layers, Sibudu Cave, South Africa. J Archaeol Sci. 2008; 35: 1566-1580.

63. Higham T, Basell L, Jacobi R, Wood R, Ramsey CB, et al. Testing models for the beginnings of the Aurignacian and the advent of figurative art and music: The radiocarbon chronology of Geils senklösterle. J Hum Evol. 2012; 62: 664-676.

64. Soffer O, Vandiver P, Klima B, Svoboda J. The Pyrotechnology of Performance Art: Moravian Venuses and Wolverines-Chapter 16. in Before Lascaux: the complex record of the early Upper Paleolithic 259-275 (CRC Press, 1993).

65. Kolen J. Hominids without homes: on the nature of Middle Palaeolithic settlement in Europe. Middle Palaeolithic Occup Eur. 1999; 139-175.

66. Mellars P. The Neanderthal Legacy: An Archaeological Perspective from Western Europe. (Princeton University Press, 1996).

67. Verpoorte A. Camps, boundaries and art. 2000.

68. Holliday VT, Hoffecker JF, Goldberg P, Macphail RI, Forman SL, et al. Geoarchaeology of the Kostenki-Borshchevo Sites, Don River Valley, Russia. Geoarchaeology. 2007; 22: 181-228.

69. Arsuaga JL, Martínez I, Gracia A, Carretero JM, Lorenzo C, et al. Sima de los Huesos (Sierra de Atapuerca, Spain). The site. J Hum Evol. 1997; 33: 109-127.

70. Delson E, Tattersall I, Van Couvering J, Brooks AS, et al. Encyclopedia of human evolution and prehistory. (Routledge, 2004).

71. Gargett RH, Bricker HM, Clark G, Lindly J, Farizyet C, et al. Grave Shortcomings: The Evidence for Neandertal Burial [and Comments and Reply]. Curr Anthropol. 1989; 30: 157-190.

72. Bar-Yosef Mayer DE, Vandermeersch B, Bar-Yosef O. Shells and ochre in Middle Paleolithic Qafzeh Cave, Israel: indications for modern behavior. J Hum Evol. 2009; 56: 307-314.

73. McCown TD, Keith A. The Stone Age of Mount Carmel. The Fossil Human Remains from the Levalloiso-Mousterian. 2 (Clarendon Press, Oxford.).

74. Horváth G, Kriska G. Striped bodypainting protects against horseflies. R Soc Open Sci. doi:doi.org/10.1098/rsos.181325
75. Giacobini G. Richness and diversity of burial rituals in the Upper Paleolithic. Diogenes. 2007; 54: 19-39.

76. Habgood PJ, Franklin NR. The revolution that didn't arrive: a review of Pleistocene Sahul. J Hum Evol. 2008; 55: 187-222.

77. Pettitt PB, Bader NO. Direct AMS radiocarbon dates for the Sungir mid Upper Palaeolithic burials. Antiquity. 2000; 74: 269-270.

78. Klima B. A triple burial from the Upper Paleolithic of Dolní Věstonice, Czechoslovakia. J Hum Evol. 1987; 16: 831-835.

79. Toro-Moyano I, Martínez-Navarro B, Agustí J, Souday C, Bermúdez de Castro JM, et al. The oldest human fossil in Europe, from Orce (Spain). J Hum Evol. 2013; 65: 1-9.

80. Swisher III CC, Curtis GH, Lewin R. Java man: how two geologists changed our understanding of human evolution. (University of Chicago Press, 2001).

81. Gibbons A. Who were the Denisovans? Science. 2011; 333: 10841087.

82. Macaulay V, Hill C, Achilli A, Rengo C, Clarke D, et al. Single, rapid coastal settlement of Asia revealed by analysis of complete mitochondrial genomes. Science. 2005; 308: 1034-1036.

83. Thorne A, Grün R, Mortimer G, Spooner NA, Simpson JJ, et al. Australia's oldest human remains: age of the Lake Mungo 3 skeleton. J Hum Evol. 1999; 36: 591-612.

84. Holzer A, Avner U, Porat N, Horwitz LK. Desert kites in the Negev desert and northeast Sinai: Their function, chronology and ecology. J Arid Environ. 2010; 74: 806-817.

85. Barnosky AD, Koch PL, Feranec RS, Wing SL, Shabel AB. Assessing the causes of Late Pleistocene extinctions on the continents. Science. 2004; 306: 70-75.

86. Smith FA, Smith REE, Lyons SK, Payne JL. Body size downgrading of mammals over the late Quaternary. Science. 2018; 360: 310-313.

87. Bar-Yosef O. The upper paleolithic revolution. Annu Rev Anthropol. 2002; 31: 363-393.

88. Botha R, Knight C. The cradle of language. 12. (OUP Oxford, 2009).

89. Harari YN, Perkins D. Sapiens: A brief history of humankind. (Harvill Secker London, 2014).

90. Diamond J. The third chimpanzee. (Oneworld Publications, 2014).

91. Hart D, Sussman RW. Man the Hunted: Primates. Predat Hum. 2005.

92. Vyshedskiy A. Development of behavioral modernity by hominins around 70,000 years ago was associated with simultaneous acquisition of a novel component of imagination, called prefrontal synthesis, and conversion of a preexisting rich-vocabulary non-recursive communication system to a fully recursive syntactic language. bioRxiv 166520 (2019). doi:https://doi.org/10.1101/166520

93. Amos W, Hoffman JI. Evidence that two main bottleneck events shaped modern human genetic diversity. Proc R Soc Lond B Biol Sci. 2010; 277: 131-137.

94. Toth N, Schick KD, Savage-Rumbaugh ES, Sevcik RA, Rumbaugh DM. Pan the tool-maker: investigations into the stone tool-making and tool-using capabilities of a bonobo (Pan paniscus). J Archaeol Sci. 1993; 20: 81-91. 
95. Semaw S, Renne P, Harris JW, Feibel CS, Bernor RL. et al. 2.5-million-year-old stone tools from Gona, Ethiopia. Nature. 1997; 385: 333

96. Hopkins WD, Fagot J, Vauclair J. Mirror-image matching and mental rotation problem solving by baboons (Papio papio): Unilateral input enhances performance. J Exp Psychol Gen. 1993; 122: 61 .

97. Vauclair J, Fagot J, Hopkins WD. Rotation of mental images in baboons when the visual input is directed to the left cerebral hemisphere. Psychol Sci. 1993; 4: 99-103.

98. Georgopoulos AP, Lurito JT, Petrides M, Schwartz AB, Massey JT. Mental rotation of the neuronal population vector. Science. 1989; 243: 234-236.

99. Mauck B, Dehnhardt G. Mental rotation in a California sea lion (Zalophus californianus). J Exp Biol. 1997; 200: 1309-1316.

100. Nielsen KJ, Logothetis NK, Rainer G. Object features used by humans and monkeys to identify rotated shapes. J Vis. 2008; 8: 9-9.

101. Dediu D, Levinson SC. On the antiquity of language: the reinterpretation of Neandertal linguistic capacities and its consequences. Front Psychol. 2013; 4: 397.

102. Emmorey K, Kosslyn SM, Bellugi U. Visual imagery and visualspatial language: Enhanced imagery abilities in deaf and hearing ASL signers. Cognition. 1993; 46: 139-181.

103. Martin AJ. Does age of language acquisition affect the relation between American sign language and mental rotation? (University of Minnesota, 2009).

104. Martin A, Senghas A, Pyers J. Age of acquisition effects on mental rotation: evidence from Nicaraguan sign language. in BUCLD 37 : proceedings of the 37 th Boston university conference on language development 241-250 (2013).

105. Pyers JE, Shusterman A, Senghas A, Spelke ES, Emmorey K. Evidence from an emerging sign language reveals that language supports spatial cognition. Proc Natl Acad Sci. 2010; 107: 1211612120 .

106. Thakkar MM, Datta S. The evolution of REM sleep. Evol. Sleep Phylogenetic Funct Perspect Camb Univ Press NY. 2010; 197-215.

107. Hobson JA. REM sleep and dreaming: towards a theory of protoconsciousness. Nat Rev Neurosci. 2009; 10: 803.

108. Sastre JP, Jouvet M. The oneiric behavior of the cat. Physiol Behav. 1979; 22: 979-989.

109. Schenck CH, Mahowald MW. REM sleep behavior disorder: clinical, developmental, and neuroscience perspectives 16 years after its formal identification in SLEEP. Sleep. 2002; 25: 120-138.

110. Ólafsdóttir HF, Barry C, Saleem AB, Hassabis D, Spiers HJ. Hippocampal place cells construct reward related sequences through unexplored space. Elife. 2015; 4: e06063.

111. Kanizsa G, Renzi P, Conte S, Compostela C, Guerani L. Amodal completion in mouse vision. Perception. 1993; 22: 713-721.

112. Fagot J, Barbet I, Parron C, Deruelle C. Amodal completion by baboons (Papio papio): contribution of background depth cues. Primates. 2006; 47: 145-150.
113. Shettleworth SJ. Do animals have insight, and what is insight anyway? Can J Exp Psychol Can Psychol Expérimentale. 2012; 66: 217.

114. Köhler W. The mentality of apes. (Harcourt, Brace \& Co., Inc. London, 1925).

115. Foerder P, Galloway M, Barthel T, Moore DE 3rd, Reiss D. Insightful problem solving in an Asian elephant. PloS One. 2011; 6: e23251.

116. Hanus D, Mendes N, Tennie C, Call J. Comparing the performances of apes (Gorilla gorilla, Pan troglodytes, Pongo pygmaeus) and human children (Homo sapiens) in the floating peanut task. PloS One. 2011; 6: e19555.

117. Hanus D, Call J. Chimpanzee problem-solving: contrasting the use of causal and arbitrary cues. Anim Cogn. 2011; 14: 871-878.

118. Epstein R, Kirshnit CE, Lanza RP, Rubin LC. 'Insight' in the pigeon: Antecedents and determinants of an intelligent performance. Nature 1984; 308: 61-62.

119. Heinrich B, Bugnyar T. Testing problem solving in ravens: Stringpulling to reach food. Ethology. 2005; 111: 962-976.

120. Petrides M, Pandya DN. Comparative cytoarchitectonic analysis of the human and the macaque ventrolateral prefrontal cortex and corticocortical connection patterns in the monkey. Eur J Neurosci. 2002; 16: 291-310.

121. Vyshedskiy A, DuBois M, Mugford E, Piryatinsky I. Development of the Linguistic Evaluation of Prefrontal Synthesis (LEPS) test for children with language delay. bioRxiv 467183 (2018).

122. Frick A, Hansen MA, Newcombe NS. Development of mental rotation in 3-to 5-year-old children. Cogn Dev. 2013; 28: 386-399.

123. Birnholz JC. The development of human fetal eye movement patterns. Science. 1981; 213: 679-681.

124. Staunton H. The function of dreaming. Rev Neurosci. 2001; 12 : 365-371.

125. Foulkes D. Children's dreaming and the development of consciousness. (Harvard University Press, 2009).

126. Kellman PJ, Arterberry ME. Infant visual perception. Handb Child Psychol. 2006.

127. Lillard AS, Pinkham AM, Smith E. Pretend play and cognitive development. Wiley-Blackwell Handb Child Cogn Dev. 2011; 32: 285.

128. Darwin C. The Descent of Man and Seletion in Relation to Sex. (John Murray, 1871).

129. Pavlov IP. Lectures on conditioned reflexes. Vol. II. Conditioned reflexes and psychiatry. (1941).

130. Vygotsky LS. Play and its role in the mental development of the child. Translated by Catherine Mulholland from Voprosy psikhologii 1933. Sov Psychol. 1967; 5: 6-18.

131. Carroll J. Reading human nature: Literary Darwinism in theory and practice. (SUNY Press, 2011).

132. Harari YN. Sapiens: A brief history of humankind. (Random House, 2014). 
133. Atance CM, O’Neill DK. Episodic future thinking. Trends Cogn Sci. 2001; 5: 533-539.

134. Suddendorf T, Redshaw J. The development of mental scenario building and episodic foresight. Ann N Y Acad Sci. 2013; 1296: 135-153.

135. Irwin SO. Embodied being: Examining tool use in digital storytelling. Tamara J Crit Organ Inq. 12, (2014).

136. Andrews-Hanna JR. The brain's default network and its adaptive role in internal mentation. The Neuroscientist. 2012; 18: 251-270.

137. Diamond A, Lee K. Interventions shown to aid executive function development in children 4 to 12 years old. Science. 2011;333: 959-964.

138. Ingvar DH. 'Memory of the future': an essay on the temporal organization of conscious awareness. Hum Neurobiol. 1985; 4: 127-136.

139. Roese NJ. Counterfactual thinking. Psychol Bull. 1997; 121: 133.

140. Suddendorf T. Two key features created the human mind inside our heads. Sci Am. 2018; 319: 43-47.

141. Voss U, Holzmann R, Tuin I, Hobson AJ. Lucid dreaming: a state of consciousness with features of both waking and non-lucid dreaming. Sleep. 2009; 32: 1191-1200.

142. Schreibman L. Diagnostic features of autism. J Child Neurol. 1988; 3: S57-S64.

143. Lovaas OI, Koegel RL, Schreibman L. Stimulus overselectivity in autism: A review of research. Psychol Bull. 1979; 86: 1236-1254.

144. Ploog BO. Stimulus overselectivity four decades later: A review of the literature and its implications for current research in autism spectrum disorder. J Autism Dev Disord. 2010; 40: 1332-1349.

145. Lovaas OI, Schreibman L, Koegel R, Rehm R. Selective responding by autistic children to multiple sensory input. J Abnorm Psychol. 1971; 77: 211.

146. Fombonne E. Epidemiological surveys of autism and other pervasive developmental disorders: an update. J Autism Dev Disord. 2003; 33: 365-382.

147. Beglinger LJ, Smith TH. A review of subtyping in autism and proposed dimensional classification model. J Autism Dev Disord. 2001; 31: 411-422.

148. Dawson G, Rogers S, Munson J, Smith M, Winter J, et al. Randomized, controlled trial of an intervention for toddlers with autism: the Early Start Denver Model. Pediatrics. 2010; 125: e17-e23.

149. American Speech-Language-Hearing Association. Scope of practice in speech-language pathology. (2016).

150. Axe JB. Conditional discrimination in the intraverbal relation: A review and recommendations for future research. Anal Verbal Behav. 2008; 24: 159-174.

151. Michael J, Palmer DC, Sundberg ML. The multiple control of verbal behavior. Anal Verbal Behav. 2011; 27: 3-22.

152. Eikeseth S, Smith DP. An analysis of verbal stimulus control in intraverbal behavior: implications for practice and applied research. Anal Verbal Behav. 2013; 29: 125-135.
153. Lowenkron B. Joint control and the selection of stimuli from their description. Anal Verbal Behav. 2006; 22: 129-151.

154. Mahapatra S, Khokhlovich E, Martinez S, Kannel B, Edelson SM, et al. Longitudinal Epidemiological Study of Autism Subgroups Using Autism Treatment Evaluation Checklist (ATEC) Score. Autism Dev Disord. 2018.

155. Romeo RR, Segaran J, Leonard JA, Robinson ST, West MR et al. Language exposure relates to structural neural connectivity in childhood. J Neurosci. 2018; 38: 7870-7877.

156. Dunn R, Jonah Elgart, Lisa Lokshina, Alexander Faisman, Edward Khokhlovich, et al. Children with autism appear to benefit from parent-administered computerized cognitive and language exercises independent of the child's age or autism severity. Autism Open Access. 2017; 7.

157. Vyshedskiy A, Dunn R. Mental Imagery Therapy for Autism (MITA)-An Early Intervention Computerized Brain Training Program for Children with ASD. Autism Open Access. 2015; 2.

158. Sacks OW. The man who mistook his wife for a hat and other clinical tales. 1st Touchstone edn. (New York, NY: Simon \& Schuster, 1998).

159. Miller BL, Cummings J, Mishkin F, Boone K, Prince F, et al. Emergence of artistic talent in frontotemporal dementia. Neurology. 1998; 51: 978-982.

\section{Correspondence to:}

Andrey Vyshedskiy, Ph.D

Boston University, Boston

USA

E-mail: vysha@bu.edu 